\title{
APOBEC3B Activity Is Prevalent in Urothelial Carcinoma Cells and Only Slightly Affected by LINE-1 Expression
}

\author{
Ananda Ayyappan Jaguva Vasudevan ${ }^{1,2 *}$, Ulrike Kreimer', Wolfgang A. Schulz', \\ Aikaterini Krikoni², Gerald G. Schumann ${ }^{3}$, Dieter Häussinger², Carsten Münk² and \\ Wolfgang Goering ${ }^{1,4 *}$
}

\begin{abstract}
${ }^{1}$ Department of Urology, Medical Faculty, Heinrich Heine University Düsseldorf, Düsseldorf, Germany, ${ }^{2}$ Clinic for Gastroenterology, Hepatology, and Infectiology, Medical Faculty, Heinrich Heine University Düsseldorf, Düsseldorf, Germany, ${ }^{3}$ Division of Medical Biotechnology, Paul-Ehrlich-Institut, Langen, Germany, ${ }^{4}$ Institute of Pathology, Medical Faculty, Heinrich Heine University Düsseldorf, Düsseldorf, Germany
\end{abstract}

The most common mutational signature in urothelial carcinoma (UC), the most common

OPEN ACCESS

Edited by:

Martin Sebastian Staege,

Martin Luther University

of Halle-Wittenberg, Germany

Reviewed by:

Harold Charles Smith, University of Rochester, United States

Gkikas Magiorkinis,

National and Kapodistrian University

of Athens, Greece

*Correspondence:

Ananda Ayyappan Jaguva Vasudevan ananda.ayyappan@med.uniduesseldorf.de Wolfgang Goering w.goering@hhu.de

Specialty section: This article was submitted to Virology,

a section of the journal Frontiers in Microbiology

Received: 15 March 2018

Accepted: 15 August 2018 Published: 04 September 2018

Citation:

Jaguva Vasudevan AA, Kreimer U, Schulz WA, Krikoni A, Schumann GG, Häussinger $D$, Münk $C$ and Goering W (2018) APOBEC3B Activity Is Prevalent in Urothelial Carcinoma Cells and Only Slightly Affected by LINE-1 Expression.

Front. Microbiol. 9:2088. doi: 10.3389/fmicb.2018.02088 type of urinary bladder cancer is assumed to be caused by the misdirected activity of APOBEC3 (A3) cytidine deaminases, especially $\mathrm{A} 3 \mathrm{~A}$ or $\mathrm{A} 3 \mathrm{~B}$, which are known to normally restrict the propagation of exogenous viruses and endogenous retroelements such as LINE-1 (L1). The involvement of A3 proteins in urothelial carcinogenesis is unexpected because, to date, UC is thought to be caused by chemical carcinogens rather than viral activity. Therefore, we explored the relationship between A3 expression and L1 activity, which is generally upregulated in UC. We found that UC cell lines highly express A3B and in some cases A3G, but not A3A, and exhibit corresponding cytidine deamination activity in vitro. While we observed evidence suggesting that $L 1$ expression has a weak positive effect on $\mathrm{A} 3 \mathrm{~B}$ and $\mathrm{A} 3 \mathrm{G}$ expression and $\mathrm{A} 3 \mathrm{~B}$ promoter activity, neither efficient siRNA-mediated knockdown nor overexpression of functional L1 elements affected catalytic activity of A3 proteins consistently. However, L1 knockdown diminished proliferation of a UC cell line exhibiting robust endogenous L1 expression, but had little impact on a cell line with low L1 expression levels. Our results indicate that UC cells express A3B at levels exceeding A3A levels by far, making A3B the prime candidate for causing genomic mutations. Our data provide evidence that L1 activation constitutes only a minor and negligible factor involved in induction or upregulation of endogenous A3 expression in UC.

Keywords: cytidine deaminase, АРОВЕСЗВ, АРОВЕСЗG, АРОВЕС3H, urothelial cancer cells, LINE-1, innate immunity, mutation

\section{INTRODUCTION}

The apolipoprotein B mRNA editing enzyme catalytic polypeptide 3 (APOBEC3, A3) protein family of $\mathrm{Zn}^{2+}$-dependent DNA cytidine deaminases constitutes a defensive network of proteins restricting exogenous viruses (Chiu and Greene, 2008; Harris and Dudley, 2015) and endogenous transposable elements (Schumann, 2007; Schumann et al., 2010; Refsland and Harris, 2013; Salter et al., 2016). They restrain retroviral replication mainly by deamination of cytidines in ssDNA following reverse transcription (Chiu and Greene, 2008; Münk et al., 2012; Vasudevan et al., 2013; 
Harris and Dudley, 2015). Importantly, APOBEC3B (A3B) is constitutively localized in the nucleus (Muckenfuss et al., 2006) and inhibits HIV-1 infection independent of the presence of Vif, which otherwise counteracts the activity of the remaining A3 family members (Bishop et al., 2004; Doehle et al., 2005). A3 proteins also inhibit human papilloma virus (HPV) and hepatitis B virus (HBV) (Harris and Dudley, 2015; Henderson and Fenton, 2015). Recently, large-scale exome and whole genome mutation studies have revealed distinct differences in mutational spectra and mutation frequencies between tumor entities (Alexandrov et al., 2013; Burns et al., 2013; Lawrence et al., 2013; Roberts et al., 2013). Many tumors of diverse entities display a characteristic mutational signature with strand-coordinated clusters of $\mathrm{C} \rightarrow \mathrm{T}$ transitions, which are frequently located in the proximity of chromosomal breakpoints. This signature is often associated with increased $A 3 A$ or $A 3 B$ mRNA expression levels and is thought to be caused by misdirected A3 activity, partly in conjunction with viral infection (Burns et al., 2013; Roberts et al., 2013). Indeed, almost all cervical cancers and a significant fraction of head and neck cancers (HNSCC), all harboring frequent A3related mutations, are associated with viral infections (Vartanian et al., 2008; Lawrence et al., 2013). Additionally, A3G expression in $\mathrm{HPV}$-induced uterine cervical intraepithelial neoplasia (CIN) and infiltration of $\mathrm{A} 3 \mathrm{G}$ expressing CD3 positive $\mathrm{T}$ cells in $\mathrm{CIN}$ lesions were reported (Iizuka et al., 2017). In contrast, the frequent occurrence of a characteristic mutational A3 signature (Lawrence et al., 2013) in urothelial carcinoma (UC) is puzzling, as these tumors are thought to be caused predominantly by chemical carcinogens rather than viral infections (Tolstov et al., 2014).

It is assumed that retroelements, including endogenous retroviruses that are flanked by long terminal repeats (LTRs), and non-LTR retrotransposons such as long interspersed nuclear element-1 (LINE-1, L1) and short interspersed nuclear elements (SINEs), have been the original targets of A3 activity and have provided the evolutionary pressure necessary for the continuous expansion of the $A 3$ locus in primates (Münk et al., 2012). Mobilization of these retroelements is restricted by the different members of the A3 protein family to protect the genome from deleterious retrotransposition events (Muckenfuss et al., 2006; Schumann, 2007; Chiu and Greene, 2008; Goodier and Kazazian, 2008; Horn et al., 2013; Orecchini et al., 2018). For instance, the role of $\mathrm{A} 3 \mathrm{~B}$ in intracellular defense against transposable element activity was recently demonstrated by a twofold to fourfold increase in retrotransposition efficiency of an engineered human L1 reporter after shRNA-based knockdown of A3B in hESCs (Wissing et al., 2011). Importantly, L1 retrotransposition has been detected during development and progression of many human cancer entities (Lee et al., 2012; Doucet-O'Hare et al., 2015; Ewing et al., 2015) (for review: Carreira et al., 2014; Goodier, 2014; Burns, 2017). In UC, the most common histological subtype of urinary bladder cancer, L1-mediated retrotransposition frequency has not been established to date. However, L1Hs elements were reported to be particularly strongly hypomethylated in UCs (Nusgen et al., 2015), full-length L1 (FL-L1) transcript levels are increased (Kreimer et al., 2013) and L1 ORF1 protein (ORF1p) can be detected in UC tissues
(Rodic et al., 2014; Whongsiri et al., 2018). Beyond L1-mediated retrotransposition, L1-encoded gene products may contribute to carcinogenesis by other mechanisms, including the regulation of RNA-DNA hybrids (Sciamanna et al., 2014; Schwertz et al., 2018). Moreover, experimental L1 downregulation in colon carcinoma cells led to reduced mRNA levels of the catalytic telomerase subunit $h T E R T$ and the telomerase RNA component hTERC (Aschacher et al., 2016). Whether this observation can be extrapolated to other cancer types like UC is so far unknown.

Conceivably, A3-induced genomic mutations may represent collateral damage to the human genome by a response originally directed against endogenous retrotransposons or exogenous viruses (Alexandrov et al., 2013). Thus, we hypothesized that in UC, where exogenous viruses are considered to contribute rarely to carcinogenesis, induction of A3 protein expression and their mutagenic effects might rather represent a response to the well-documented activation of endogenous L1 retrotransposons in these tumors. To address this hypothesis, we analyzed the mRNA expression profile of the different A3 family members in UC cell lines, which we had previously characterized for FL-L1 expression (Kreimer et al., 2013) and established the actual presence of A3-specific enzymatic activity. Subsequently, we investigated the consequences of modulating L1Hs expression by siRNA-mediated knockdown or ectopic overexpression for A3 expression and cellular properties. While UC cell lines did not express detectable $A 3 A$ mRNA levels, expression of $A 3 B$ mRNA was prominent in many. Our experiments provide evidence that there is only some minor effect of L1Hs expression on A3B promoter activity, which alone cannot explain the extensive upregulation of $\mathrm{A} 3 \mathrm{~B}$ expression in UC tissues and cell lines. Modulation of L1 expression did not have any consistently detectable effect on the expression of endogenous $\mathrm{A} 3 \mathrm{~A}, \mathrm{~A} 3 \mathrm{~B}$, or $\mathrm{A} 3 \mathrm{G}$, even though knockdown of L1 elements with intact ORF1p impeded cell growth.

\section{MATERIALS AND METHODS}

\section{Tissue Samples and Cell Lines}

All urothelial cancer cell lines (UCCs) used in this study (253J, 5637, 639-V, 647-V, BFTC905, HT-1376, J82, MGHU4, RT4, RT-112, SCaBER, SD, SW-1710, UMUC3, UMUC6, VM-CUB1, T24) were cultured in DMEM GlutaMax (Gibco, Darmstadt, Germany), supplemented with $10 \%$ fetal calf serum (Koch et al., 2012). BC61 cells were cultured as described previously (Seifert et al., 2007). The cell lines were obtained from the Leibniz Institute DSMZ-German Collection of Microorganisms and Cell Cultures (Braunschweig, Germany), except for the cell line UMUC3, which was kindly provided by Dr. Grossman (Houston, TX, United States). The human embryonal carcinoma cell lines NCCIT (ATCC CRL-2073) and Tera-1 (ATCC HTB-105) were kindly provided by Dr. R. Loewer, (Paul-Ehrlich-Institut, Langen, Germany) and cultured as described (Hoffmann et al., 2006). HeLa cells (ATCC CCL-2) were cultured following supplier's recommendations. The telomerase-immortalized TERT-NHUC 
cell line was kindly provided by Dr. M. A. Knowles (Leeds, United Kingdom) and cultured as described (Chapman et al., 2009). Cell lines were authenticated prior to use by STR profiling in the Institute of Forensic Medicine, Heinrich Heine University Düsseldorf, Germany. Cultures of primary urothelial (UP) cells were established from ureters after nephrectomy and were routinely maintained in keratinocyte serum-free medium (KSFM, Gibco, Darmstadt, Germany) supplemented with $12.5 \mu \mathrm{g} / \mathrm{ml}$ bovine pituitary extract and $0.25 \mathrm{ng} / \mathrm{ml}$ epidermal growth factor as described (Swiatkowski et al., 2003). Tissue samples for UP generation were collected with patient informed consent and approval by the ethics committee of the medical faculty of the Heinrich Heine University, Study Number 1788.

\section{Nucleic Acid Extraction and cDNA Synthesis}

To minimize DNA contamination, total RNA was extracted by acid phenol extraction followed by column purification. Synthesis of complementary DNA was performed using the QuantiTect Reverse Transcription Kit (Qiagen, Hilden, Germany), according to the manufacturer's instructions, including an extra DNA removal step by DNase as recommended by the supplier. Briefly, $1 \mu \mathrm{g}$ of total RNA was subjected to genomic DNA elimination reaction in a $14 \mu \mathrm{l}$ volume, comprised of $2 \mu \mathrm{l}$ of a $7 x$ gDNA-Wipeout-Buffer, RNA, and water. The reaction mixture was incubated at $42^{\circ} \mathrm{C}$ for 2 min and then kept on ice. One microliter of the reaction mixture was taken and mixed with $14.38 \mu l$ of water in a new tube (considering $1 \mu \mathrm{g}$ total RNA input, the RNA concentration in this solution would be $4.64 \mathrm{ng} / \mu \mathrm{l}$ ), which served as mock RT template for RT-qPCR assay. With the remaining $13 \mu \mathrm{l}$ reaction mixture, cDNA synthesis was performed $(20 \mu$ l volume reaction mixture is made up of $1 \mu \mathrm{l} \mathrm{RT}, 4 \mu \mathrm{l}$ RT buffer $(5 \mathrm{x}), 1 \mu \mathrm{l}$ RT primer mix, $1 \mu$ l water, and $13 \mu$ l DNAse treated RNA) by incubating the $\mathrm{RT}$ reaction components for $30 \mathrm{~min}$ at $42^{\circ} \mathrm{C}$ and then inactivating the RT enzyme by boiling for $95^{\circ} \mathrm{C}$ for $3 \mathrm{~min}$ (according to the manufacturer's instruction). In order to minimize potential inhibitory effects of the RT buffer system on qPCR, a 1:10 dilution of the cDNA product was generated prior to the PCR reaction quantifying FLL1 transcripts. The final nucleic acids concentration of the RNA suspension (used for the Mock RT-qPCR) and the CDNA suspension were both adjusted to $4.64 \mathrm{ng} / \mu \mathrm{l}$ prior to qPCR.

The efficiency of DNAse treatment was assessed by qPCR on RNA samples that were not incubated with any Reverse Transcriptase before. Data (Ct values) obtained from cell lines 5637, VM-CUB1, 639-V, SD, BC61, RT4 are provided in Supplementary Table 1 . Ct values obtained from mock-RT experiments were found to be comparable with those obtained from blank control (water). The qPCR conditions were as follows: initial denaturation step at $95^{\circ} \mathrm{C}$ for $15 \mathrm{~min}$, followed by 40 amplification cycles consisting of denaturation at $95^{\circ} \mathrm{C}$ for $15 \mathrm{~s}$, annealing at $55^{\circ} \mathrm{C}$ for $20 \mathrm{~s}$ and extension at $72^{\circ} \mathrm{C}$ for $30 \mathrm{~s}$, using the primers presented in the following method section and Supplementary Table 2 .

\section{Quantitative Real-Time Reverse Transcription PCR (RT-qPCR)}

RT-qPCR was performed on a 7500 Fast Real-Time PCR System (Applied Biosystems, Carlsbad, CA, United States) or Roche LightCycler 96 (Hoffmann-La Roche Ltd., Basel, Switzerland) using the QuantiTect SYBR Green PCR Kit (Qiagen, Hilden) with cDNA (1:10 diluted) from DNAse-treated RNA samples (see also above) as described previously (Goering et al., 2011). To quantify transcripts, specifically designed primers (Supplementary Table 2) were employed using the following PCR conditions: initial denaturation at $95^{\circ} \mathrm{C}$ for $15 \mathrm{~min}$, followed by 40 amplification cycles consisting of denaturation at $95^{\circ} \mathrm{C}$ for $15 \mathrm{~s}$, annealing at the appropriate temperature for $20 \mathrm{~s}$ and extension at $72^{\circ} \mathrm{C}$ for $30 \mathrm{~s}$. Assay specificity was controlled for by using UCSC In-Silico PCR and melting curve profiles. All measurements were performed at least in duplicates; assay variance was $<10 \%$. Relative expression was calculated by the modified $\Delta \Delta \mathrm{Ct}$ method using TATA-box binding protein (TBP) mRNA levels as a reference gene transcript (Pfaffl, 2001). To ascertain efficient amplification, a standard curve was carried in each RT-qPCR experiment using cDNAs from activated PBMCs ( $A 3 A, A 3 F, A 3 H)$, UMUC3 (A3B, A3D), PC3 (A3C, TBP), 5637 $(A 3 G)$, and VM-CUB1 (FL-L1), respectively.

To quantify transcript levels of human endogenous FLL1 elements, primers specific for the $5^{\prime}$-UTR sequence of the L1.3 reference element (Acc. No. L19088.1, Sassaman et al., 1997) were used which bind L1.3 nucleotide positions 99120 (L1_5'_for: 5'-GTACCGGGTTCATCTCACTAGG-3') and 323-344 (L1-5'_rev: 5'-TGTGGGATATAGTCTCGTGGTG-3') (Supplementary Table 2). RT-qPCRs with these primers were performed as previously described (Kreimer et al., 2013).

\section{Immunoblot Analysis}

Twenty micrograms of each protein lysate were boiled in 3x SDS sample buffer (New England Biolabs, Frankfurt/Main, Germany), loaded on $4-12 \%$ Bis/Tris gels (Invitrogen), subjected to SDSPAGE, and electroblotted onto nitrocellulose membranes. After protein transfer, membranes were blocked for $2 \mathrm{~h}$ at room temperature in $10 \%$ non-fat milk powder in 1xPBS-T [137 mM $\mathrm{NaCl}, 3 \mathrm{mM} \mathrm{KCl}, 16.5 \mathrm{mM} \mathrm{Na}_{2} \mathrm{HPO}_{4}, 1.5 \mathrm{mM} \mathrm{KH}_{2} \mathrm{PO}_{4}, 0.05 \%$ Tween 20 (Sigma-Aldrich, Mannheim, Germany)], washed in $1 \mathrm{xPBS}-\mathrm{T}$, and incubated overnight with the respective primary antibody at $4^{\circ} \mathrm{C}$.

L1 ORF1p was detected using the polyclonal rabbit-anti-L1 ORF1p antibody \#984 (Raiz et al., 2012) at a 1:2,000 dilution in $1 \mathrm{xPBS}-\mathrm{T}$ containing $5 \%$ milk powder as primary antibody. Subsequently, membranes were washed three times in 1xPBST. As secondary antibodies, we used HRP-conjugated donkey anti-rabbit IgG antibody at a 1:30,000 dilution (Amersham Biosciences, Freiburg, Germany) in 1xPBS/5\% milk powder for $2 \mathrm{~h}$. Subsequently, the membrane was washed three times for $10 \mathrm{~min}$ in $1 \mathrm{xPBS}-\mathrm{T}$. $\beta$-actin expression was detected using a monoclonal anti- $\beta$-actin antibody (clone AC-74, SigmaAldrich, Steinheim, Germany) at a dilution of $1: 30,000$ as primary antibody and an anti-mouse HRP-linked species-specific antibody (from sheep) at a dilution of 1:10,000 as secondary 
antibody. Immunocomplexes were visualized using luminobased ECL immunoblot reagent (Amersham Biosciences). For the immunoblot analysis shown in Figure 2D, the applied monoclonal anti-L1 ORF1p antibody was kindly provided by Dr. K. Burns (Johns Hopkins University, Baltimore, MD, United States) (Rodic et al., 2014) or purchased (clone 4H1, 1:10,000 dilution, Millipore, Darmstadt, Germany). For immunoblot detection of $\mathrm{A} 3 \mathrm{H}$ protein in selected UCCs, antiHuman APOBEC3H monoclonal antibody (P1H6, cat \# 12156, $1: 10^{3}$ dilution, NIH AIDS reagent) was used.

\section{Transfection Experiments}

In order to knockdown expression of functional endogenous L1 elements, cells were transfected for $72 \mathrm{~h}$ with $20 \mathrm{nmol}$ of either L1_siRNA\#1 (5'-GAGAACGCCACAAAGAUACtt-3') (Oricchio et al., 2007) or L1_siRNA\#2 (5'-GAAAUGAAGC GAGAAGGGAAGUUUA-3') (Aschacher et al., 2016) targeting specifically nucleotide positions $1512-1531$ or $1287-1312$ of the L1.3 reference sequence (acc.no: L19088.1; Sassaman et al., 1997), respectively, (Supplementary Table 2) or a non-specific control (Silencer select negative control siRNA 1; Life Technologies, Darmstadt, Germany). Transfections were performed using Lipofectamine RNAiMAX (Life Technologies) according to the manufacturer's instructions. The chosen siRNAs specifically target roughly 500 full-length and truncated L1 elements in the average human genome of L1PA1 subfamily L1Hs sequences, which can be transcriptionally active (Skowronski et al., 1988; Sheen et al., 2000; Tang et al., 2017). To ensure that the siRNA effects persist in long-term $(120 \mathrm{~h})$ experiments, the siRNA transfection procedure was repeated 3 days after the initial transfection. Knockdown of $A 3 B$ and $A 3 G$ expression was accomplished by transient transfection of siRNAs (Cat. Nos. L-017322-00 and L-013072-00, Dharmacon/ON-TARGETplus siRNA Reagents) for $72 \mathrm{~h}$. As indicated in Figure 4, the total concentration of siRNAs was maintained at $20 \mathrm{nM}$ for all transfections.

The episomal L1 retrotransposition reporter plasmids pJM101/L1 $1_{R P}$ (Kimberland et al., 1999) and pAJG101/L1 $1_{R P}$ (Supplementary Figure 1) facilitating ectopic expression of the mneoI-tagged, full-length $\mathrm{L}_{R P}$ element, and their empty vector pCEP4 (Thermo Fisher Scientific) were separately transfected into UC cells using the X-tremeGENE 9 DNA transfection reagent (Roche). In $\mathrm{pAJG} 101 / \mathrm{L} 1_{R P}$ the $\mathrm{CMV}$ promoter in pJM101/L1 $1_{R P}$ was replaced by the CAG promoter (Niwa et al., 1991; Kobayashi, 1996).

\section{A3B Promoter Constructs and Reporter Assays}

For this study, we have constructed two $A 3 B$ promoter luciferase reporter constructs pA3B-120 and pA3B-1200 (Supplementary Figure 2). To generate pA3B-1200, the genomic sequence flanked by nucleotide position -1200 and +18 relative to the ATG start codon of the $A 3 B$ gene was amplified from genomic HeLa DNA applying forward primer A3B_Pr_-1200_F (5'-GATGGTACC GCTCCCAGCAACCCCCCAG) and reverse primer A3B_Pr_ -1200_R (5'-CATGCTAGCCTGATCTGTGGATTCATGTTCA
GC) and Pwo DNA polymerase (Roche) using the following PCR conditions: one cycle $94^{\circ} \mathrm{C}$ for $2 \mathrm{~min}$; 30 cycles of $94^{\circ} \mathrm{C}$ for $30 \mathrm{~s}, 58^{\circ} \mathrm{C}$ for $60 \mathrm{~s}$, and $72^{\circ} \mathrm{C}$ for $60 \mathrm{~s}$; one cycle $72^{\circ} \mathrm{C}$ for $7 \mathrm{~min}$. The amplicon was inserted into the promoterless luciferase reporter plasmid pGL3-Basic (Promega, Mannheim, Germany) via KpnI and NheI restriction sites in the primer sequences (Supplementary Figure 2).

pGL3-Basic (Promega) derived reporter plasmid pA3B-120 containing a 120-bp fragments of the $\mathrm{A} 3 \mathrm{~B}$ promoter was constructed from pA3B-1200 using forward primer A3B_Pr_120_F (5'-GATGGTACCGCCCTGGGAGGTCACTTTAAG) and reverse primer A3B_Pr_-1200_R (Supplementary Figure 2). UC cells 5637 and VM-CUB1 were plated in 24-well dishes and cotransfected with either pA3B-120 or pA3B-1200 and either $\mathrm{pJM} 101 / \mathrm{L} 1_{R P}$ or $\mathrm{pAJG} 101 / \mathrm{L} 1_{R P}$ on the next day using $\mathrm{X}$-tremeGENE 9 DNA transfection reagent (Roche). The cells were cotransfected with each A3B-promoter-luciferase reporter construct or the $\triangle \mathrm{HOX}$ plasmid, containing a frameshifted HOXB13 cDNA in pcDNA/TO4, as a MOCK-transfection control. Luciferase activity was quantified 2 days post transfection using the Dual Luciferase Reporter Assay System (Promega, Mannheim, Germany) as described (Goering et al., 2011).

\section{APOBEC3 Detection and in vitro DNA Deamination Assay}

HEK293T cells were transfected with plasmids expressing hemagglutinin (HA)-tagged A3B or A3G using Lipofectamine LTX (Thermo Fisher Scientific). 5637, UMUC3 and VMCUB1 UCCs were transfected with the $\mathrm{pJM} 101 / \mathrm{L} 1_{R P}$ expression construct or $\triangle \mathrm{HOX}$ as a MOCK-transfection control as described above. Seventy-two hours later, cells were washed in PBS and lysed with a mild lysis buffer [50 mM Tris ( $\mathrm{pH}$ 8), $1 \mathrm{mM}$ PMSF, $10 \%$ glycerol, $0.8 \%$ NP-40, $150 \mathrm{mM} \mathrm{NaCl}$ and $1 \mathrm{X}$ complete protease inhibitor (Calbiochem, Darmstadt, Germany)]. Lysates were clarified by centrifugation for $20 \mathrm{~min}$ at $14,800 \mathrm{rpm}$ at $4^{\circ} \mathrm{C}$. For immunoblot analyses, samples were boiled at $95^{\circ} \mathrm{C}$ for $5 \mathrm{~min}$ in Roti load reducing buffer (Roth, Karlsruhe, Germany), separated on an SDS-PAGE gel followed by transfer to a PVDF membrane. Membranes were blocked in TBST containing 5\% skimmed milk powder and probed with the respective primary antibody. A rabbit anti-A3G antibody (anti-ApoC17; 1:10 ${ }^{4}$ dilution, NIH AIDS reagent) that is crossreactive against $\mathrm{A} 3 \mathrm{~A}$ and $\mathrm{A} 3 \mathrm{~B}$ was used to detect $\mathrm{A} 3 \mathrm{~B}$ and A3G proteins (Mitra et al., 2014; Jaguva Vasudevan et al., 2018). Mouse anti- $\alpha$-tubulin antibody (1:4,000 dilution, clone B5-12; Sigma-Aldrich, Taufkirchen, Germany), or goat anti-GAPDH (C-terminus, 1:15,000 dilution, Everest Biotech, Oxfordshire, United Kingdom) were used as primary antibodies for loading controls.

In vitro deamination reactions were performed as described (Nowarski et al., 2008; Jaguva Vasudevan et al., 2013) in a

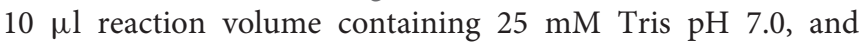
$100 \mathrm{fmol}$ single-stranded DNA substrate (CCCA : 5'-GGATTGG TTGGTTATTTGTTTAAGGAAGGTGGATTAAAGGCCCAAG AAGGTGATGGAAGTTATGTTTGGTAGATTGATGG; TTCA: 5'-GGATTGGTTGGTTATTTGTATAAGGAAGGTGGATTGA 
AGGTTCAAGAAGGTGATGGAAGTTATGTTTGGTAGATTG ATGG) with $2 \mu \mathrm{l}$ of freshly prepared cell lysate. Samples were divided in half and $50 \mu \mathrm{g} / \mathrm{ml}$ RNase A (Thermo Fisher Scientific) were added to one half. Subsequently, reactions were incubated for $1 \mathrm{~h}$ at $37^{\circ} \mathrm{C}$ and the reaction was terminated by incubating samples at $95^{\circ} \mathrm{C}$ for $5 \mathrm{~min}$. An equivalent of one fmol single-stranded DNA substrate was used for PCR amplification [Dream Taq polymerase (Thermo Scientific)] comprising $95^{\circ} \mathrm{C}$ for $3 \mathrm{~min}$, followed by 30 cycles of $61^{\circ} \mathrm{C}$ for $30 \mathrm{~s}$ and $94^{\circ} \mathrm{C}$ for $30 \mathrm{~s}$ ) using the forward primers $5^{\prime}$-GATTGGTTGGTTATTTGTTTAAGGA for the CCCA substrate or $5^{\prime}$-GGATTGGTTGGTTATTTGTATAAGGA for the TTCA substrate, and in both cases the reverse primer 5 '-CCATCAATCTACCAAACATAACTTCCA. PCR products resulting from the CCCA and TTCA substrates were digested with the restriction enzymes Eco147I (StuI) (Thermo Fisher Scientific) or MseI (NEB, Frankfurt/Main, Germany), respectively, and the resulting restriction fragments were separated on a $15 \%$ native PAGE gel and stained with ethidium bromide solution $(7.5 \mu \mathrm{g} / \mathrm{ml})$. To control for successful and efficient restriction digestion of the PCR products, additional substrate oligonucleotides in which the nucleotide sequences $5^{\prime}$-CCCA- $3^{\prime}$ and $5^{\prime}$-TTCA- $3^{\prime}$ were replaced by $5^{\prime}$-CCUA- $3^{\prime}$ and $5^{\prime}$-TTUA- $3^{\prime}$, respectively, were digested in parallel.

\section{Cell Viability, Proliferation, Apoptosis, and Senescence-Associated (SA)- $\beta$-Galactosidase Assays}

Cell viability and apoptosis were assessed in quadruplicates by CellTiter-Glo ${ }^{\circledast}$ Luminescent Cell Viability Assay and CaspaseGlo $^{\circledR}$ 3/7 Assay (Promega, Madison, WI, United States), respectively, using a Wallac 1420 VICTOR2 $2^{\mathrm{TM}}$ plate reader (PerkinElmer, Waltham, MA, United States). Cell proliferation was measured by an EdU incorporation assay (baseclick $\mathrm{GmbH}$, Neuried, Germany), according to the manufacturer's instructions. The SA- $\beta$-galactosidase assay was performed as described (Itahana et al., 2007).

\section{Clonogenicity Assay}

For clonogenicity assays, cells were plated at low density into $6 \mathrm{~cm}$ dishes and grown until colonies started to become confluent for the fastest growth condition. Colonies were stained with Giemsa (Merck, Darmstadt, Germany).

\section{Analysis of $A 3 H$ Single Nucleotide Polymorphism (SNP)}

Since $A 3 H$ haplotype I encodes an active cytosine deaminase described to reside in the nucleus and linked to cancer mutagenesis (Starrett et al., 2016), the status of $A 3 H$ SNPs was determined in our panel of UCCs. A 305-bp genomic DNA genomic DNA fragment of the $A 3 H$ gene was amplified from DNAs from various UCCs using primer pairs, $\mathrm{A} 3 \mathrm{H}$ forward 5'-AGTGCCATGCAGAAATTTGCTTT and A3H reverse 5'CGGGGGTTTGCACTCTTATAACT. Amplified fragments were subjected to direct Sanger sequencing and results were analyzed for the highly polymorphic SNP rs139297 and the adjacent SNPs rs139298/rs139299.

\section{Statistical Analyses}

$p$-Values were calculated by the Mann-Whitney $U$ Test using SPSS Statistics 21 (IBM, Armonk, NY, United States) the unpaired Student's $t$-test with Graphpad Prism (GraphPad Software, San Diego, CA, United States). Data were represented as the mean \pm standard deviation (SD). Significant differences $(p<0.05)$ are marked by asterisks. Correlation coefficients and significance were calculated by non-parametric Spearman's rank correlation (Spearman's rho) and were corrected for multiple testing using the Bonferroni method.

\section{RESULTS}

\section{A3B Is Upregulated in Urothelial Cancer Cells}

As a first step to investigate if the expression of specific members of the A3 protein family of cytidine deaminases is a response to the upregulation of endogenous L1 expression, we profiled mRNA levels of all seven members of the A3 protein family $(A 3 A, A 3 B, A 3 C, A 3 D, A 3 F, A 3 G$, and $A 3 H)$ in 19 UCCs and five independent primary cultures of normal urothelial cells (UPs) by RT-qPCR. A3A was only detectable in the urothelial cell culture UP86, the UCC BFTC905 (Figure 1 and Supplementary Figure 3) and in activated PBMCs serving as positive control for $A 3 A$ expression (data not shown). $A 3 A$ expression was not detectable in all remaining UCCs and UPs. In contrast, $A 3 B$ expression was barely detectable in all analyzed urothelial cell cultures, but was high in all analyzed UCCs except for the $647-\mathrm{V}$ line harboring no detectable $A 3 B$ mRNA at all (Figure 1 and Supplementary Figure 3). $A 3 C$, $D$, and $F$ transcripts were detectable at moderate levels in all tested UPs and the majority of UCCs, but a few UCCs expressed $A 3 C$ and $A 3 D$ at extremely low or undetectable levels (Figure 1 and Supplementary Figure 3). $A 3 G$ expression was robust in UPs but low in most UCCs, especially in those originating from muscle-invasive urothelial cancers (Figure 1 and Supplementary Figure 3). $A 3 H$ transcripts were below detection level in the majority of muscle-invasive UCCs and in two UPs, while the remaining cell lines and UP cultures displayed moderate or robust transcript levels. In the papillary UCC BC61, $\mathrm{A} 3 \mathrm{H}$ expression was exceptionally upregulated (Figure $\mathbf{1}$ and Supplementary Figure 3).

Quantification of FL-L1 transcripts revealed moderate L1 expression in all UPs and robust transcriptional L1 upregulation in almost all analyzed UCCs with the exception of the UCCs 253J and 5637 (Figure 1 and Supplementary Figure 3). If L1 upregulation contributed to activation of A3 enzymes, mRNA expression of L1 and $A 3$ would be expected to correlate. We therefore calculated whether any correlation between FL-L1 mRNA expression levels and mRNA levels of the various $A 3$ genes could be detected in UCCs using Spearmen's rho correlation (Figure 1, see also Kreimer et al., 2013). Surprisingly, only the correlation between $\mathrm{L} 1$ and $A 3 H$ RNA levels reached the level of 


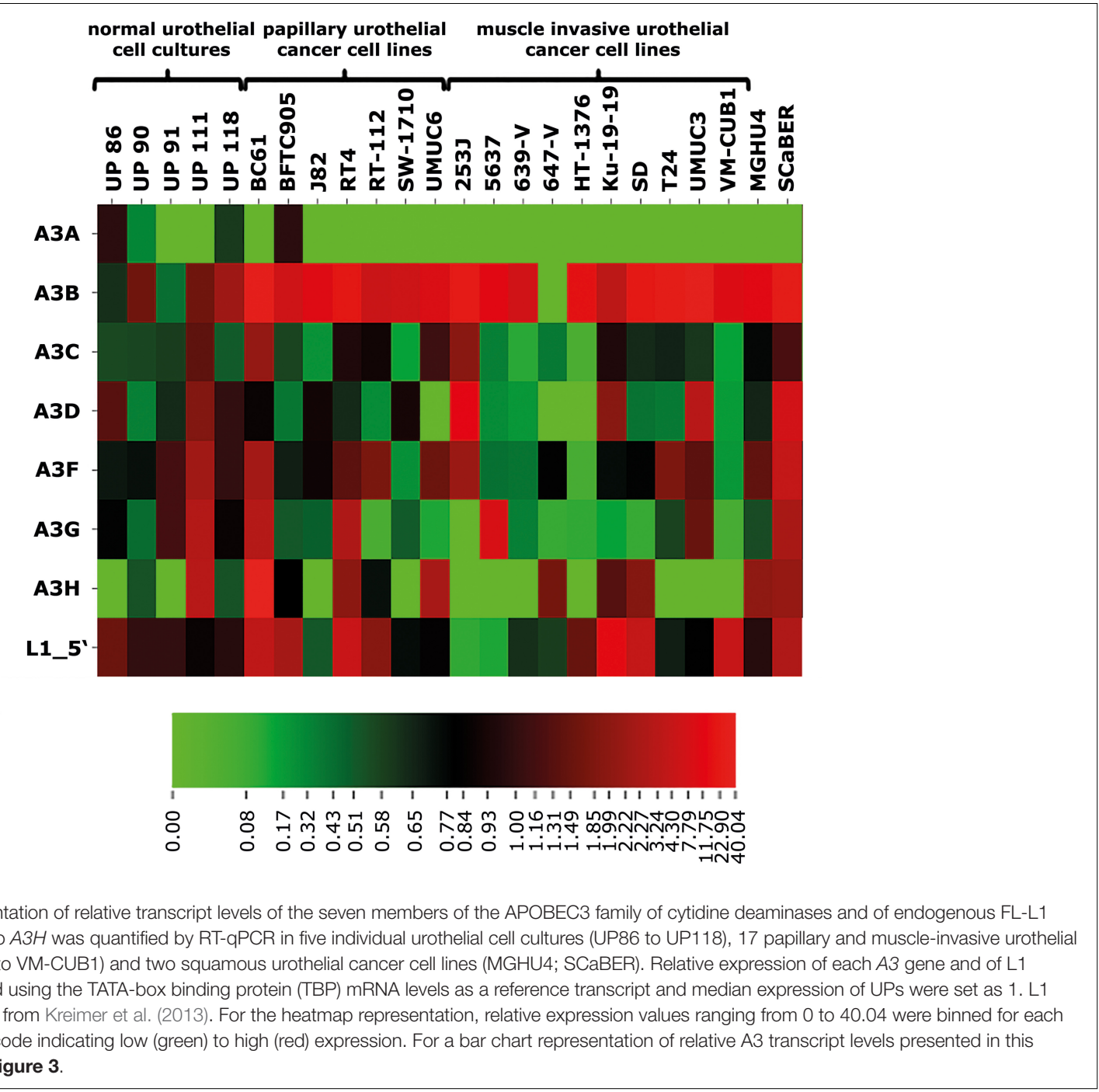

significance (Spearman's rho $0.419,{ }^{*} p=0.042$ ), which was lost after Bonferroni correction for multiple testing.

Because $A 3 H$ was expressed in several UPs and $A 3 H$ haplotype I $(A 3 H-I)$, a specific allele of $A 3 H$, has been implicated in breast and lung carcinogenesis (Starrett et al., 2016), we additionally determined the $A 3 H$ genotype at SNPs rs139297, rs139298 and rs139299 in UCCs (Supplementary Table 3). Approximately two thirds of the tested UCCs harbor the G105/K121 allele associated with the $A 3 H-I$ haplotype in a homozygous (6/18) or heterozygous (7/18) manner. However, expression of $\mathrm{A} 3 \mathrm{H}$ was not detectable in selected UCCs irrespective of the $A 3 H$ genotype (Supplementary Figure 7). This finding implies $A 3 H$ as a possible but unlikely source of A3 mutations in several but not all UCCs.

\section{L1 ORF1p Is Expressed in Most UCCs}

The design of the L1-specific RT-qPCR assay to quantify L1 transcript levels (Kreimer et al., 2013; Figure 1) which is based on the L1.3 reference sequence (Sassaman et al., 1997), does not allow to fully distinguish transcripts of the approximately
100 retrotransposition-competent L1Hs elements (Brouha et al., 2003) encoding functional L1 ORF1 and L1 ORF2 proteins from non-functional FL-L1 transcripts. Therefore, to investigate relative expression levels of $\mathrm{L} 1 \mathrm{Hs}$ elements encoding functional L1 proteins, we performed quantitative immunoblot analyses using anti-L1-ORF1p antibodies (Raiz et al., 2012; Rodic et al., 2014).

Consistent with their previously assessed relative FL-L1 mRNA levels (Kreimer et al., 2013) (Figure 1), elevated amounts of L1 ORF1p were detected in the UCC lines BFTC905, RT-112, VM-CUB1, and SD (Figure 2A and Supplementary Figures $4 \mathrm{~A}, \mathrm{C}$ ). More moderate but still detectable L1 ORF1p levels were present in J82, SW-I710, UMUC6, 253J, 5637, 639V, 647-V, HT-1376, T24, and UMUC3 cells (Supplementary Figure 4). The relatively modest amounts of L1 ORF1p in BC61 and RT4 cells do not seem consistent with the transcriptional L1 upregulation in these cells (Figure 1), but could be explained by the fact that a subset of FL-L1 elements transcribed in these cell lines does not encode intact L1 proteins. Of note, L1 ORF1p expression was not detectable in the normal urothelial cell culture 

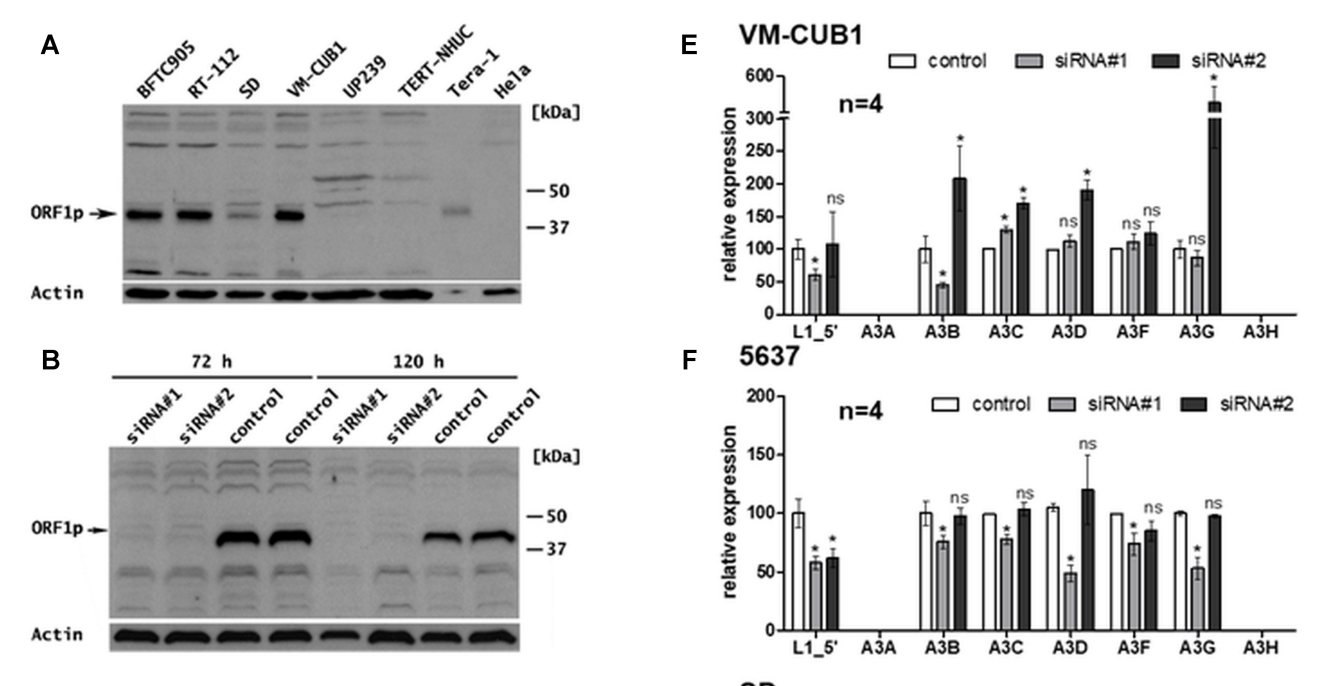

$\mathbf{F}$
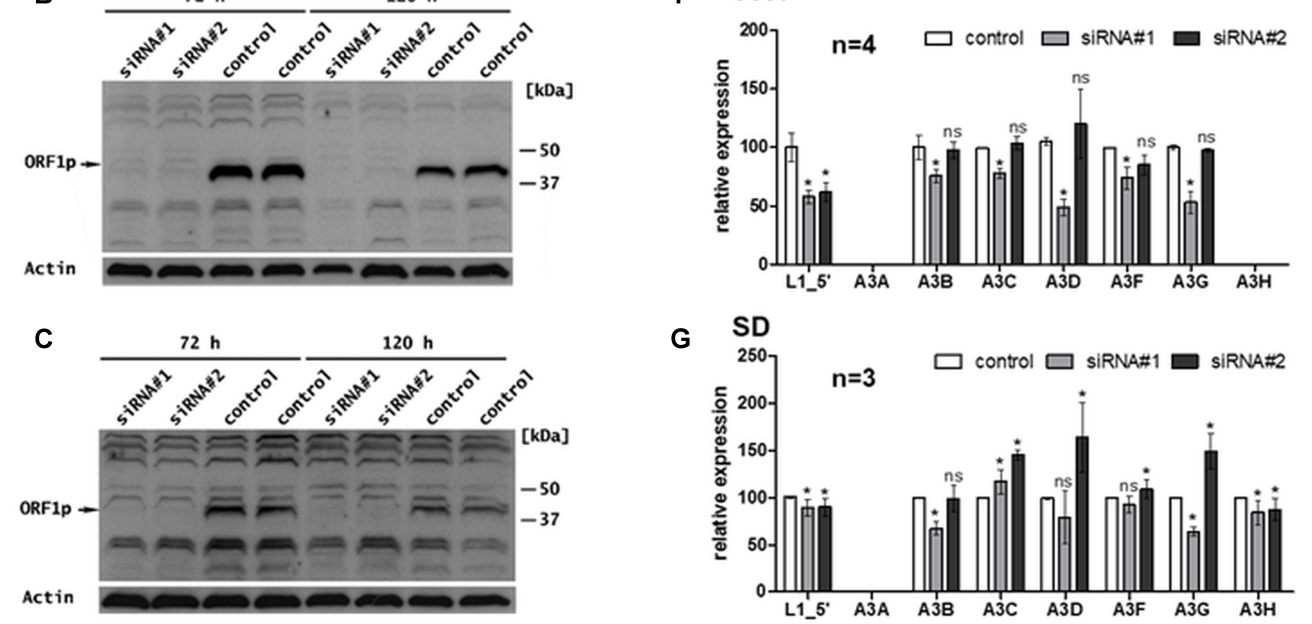

G
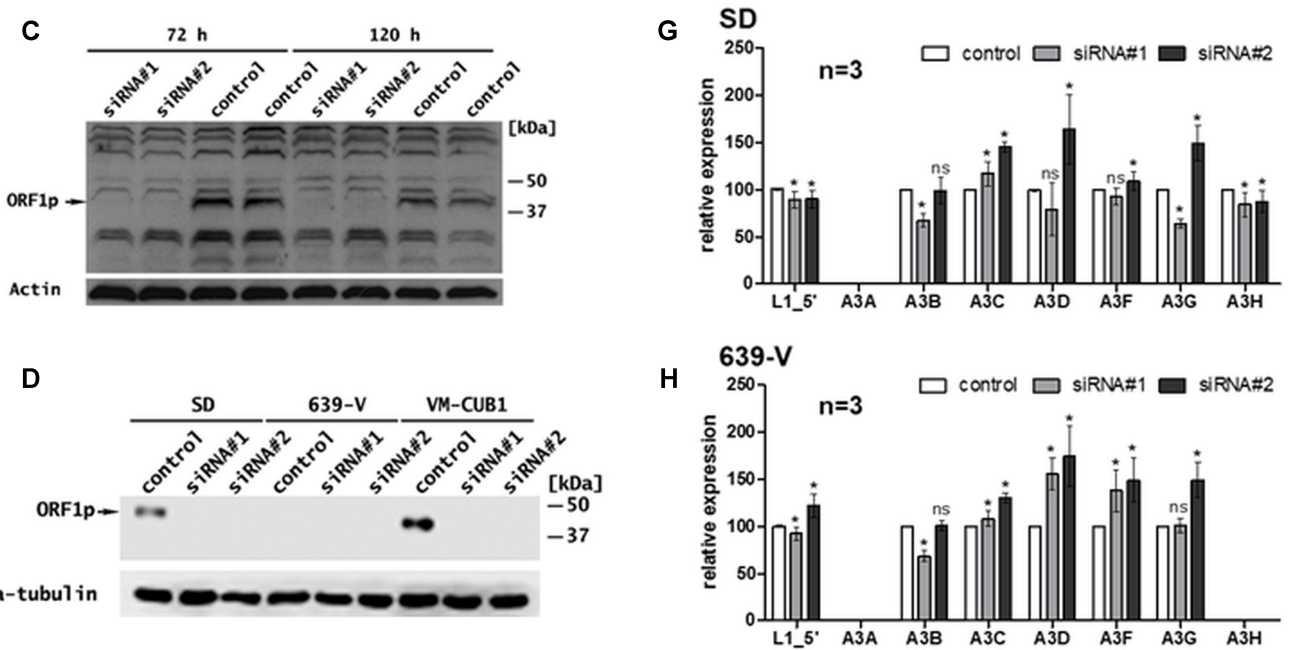

FIGURE 2 | Effects of transcriptional knockdown of endogenous FL-L1 expression on transcription of the APOBEC3 gene family members in UCCs. (A) L1 ORF1p expression was analyzed in selected UCCs (BFTC905, RT-112, SD, and VM-CUB1) and benign urothelial samples (UP239, TERT-NHUC) by immunoblot analyses using an anti-ORF1p antibody. Tera-1 (highly diluted) and HeLa protein extracts were used as positive and negative control for L1 ORF1p expression, respectively. L1 ORF1p expression was determined in VM-CUB1 (B), 5637 (C), SD, and 639-V (D) UCCs after treatment with $20 \mathrm{nM}$ control or L1-specific siRNAs for $72 \mathrm{~h}$ (B,C) and $120 \mathrm{~h}$ (B-D) by immunoblot analysis. $\beta$-actin or tubulin protein was detected as loading control. Note longer exposure in (C). In (D) VM-CUB1 served as a positive control for siRNA treatment. mRNA expression of L1, A3A, A3B, A3C, A3D, A3F, and A3G was assessed in VM-CUB1 (E), 5637 (F), SD (G), and 639-V (H) UCCs by RT-qPCR after $72 \mathrm{~h}$ treatment with $20 \mathrm{nM}$ LINE-1 specific siRNAs and control siRNA. Relative expression levels were calculated using TBP mRNA levels as a reference transcript and expression in control siRNA treated samples were set as 100. "n" represents the number of independent knock down experiments. Data were represented as means \pm standard deviations (error bars). $P$-values were calculated using $t$-tests. Asterisk represents statistically significant difference: $* P<0.05$ and $\mathrm{ns}$, not significant.

UP239 and the TERT-NHUC immortalized normal urothelial cell line (Figure 2A).

\section{L1 siRNA-Mediated Knock Down of Functional, Endogenous L1 Elements in UCCs Exert Largely Diverse Effects on A3 Expression}

In order to investigate potential effects of L1-encoded gene products on the expression of $\mathrm{A} 3$ proteins, we modulated the expression of L1 elements in selected representative UCCs with robust endogenous $\mathrm{A} 3 \mathrm{~B}$ transcription levels and either low/moderate (5637 and 639-V) or high (VM-CUB1 and SD) L1 mRNA and ORF1p expression levels, respectively. Expression of full-length L1Hs elements was downregulated in the four UCCs by transfecting either siRNA\#1 (Oricchio et al., 2007) or siRNA\#2 (Aschacher et al., 2016), which are specifically directed against ORF1 of the human L1.3 reference sequence (Sassaman et al., 1997; see Materials and Methods).

Transfection of each of the two L1-specific siRNAs efficiently knocked down L1 ORF1p expression in VM-CUB1 (Figures 2B,D), 5637 (Figure 2C), and SD UCCs. L1 mRNA and ORF1p expression was barely detectable in $639-\mathrm{V}$ and remained unchanged after L1 siRNA treatment (Figures 1, 2D). 
Interestingly, RT-qPCR using primer combinations specific for the $5^{\prime}$ end of the L1 $5^{\prime}$-UTR (see Materials and Methods and Supplementary Table 2) revealed that overall FL-L1 transcript levels were reduced only by at most $50 \%$ (Figures $\mathbf{2 E - H}$ ). Since the partial mRNA knockdown observed in these cell lines nevertheless resulted in a highly efficient L1 ORF1p depletion (Figures 2A-D), this observation indicates that the siRNAs target most if not all intact protein-coding L1 elements harboring an intact ORF1 efficiently. In contrast, non-functional FL-L1 elements with mutations in ORF1 that differ from the L1.3 reference sequence were targeted less efficiently.

Following transfection with L1-specific siRNAs, $A 3 A$ mRNA expression remained undetectable in all four UCC lines (Figures 2E-H). A3H expression was only detectable in SD cells among these four UCCs (compare with Figure 1) and not altered by the knockdown of L1 expression in the examined UCCs (Figures 2E-H), whereas L1 knockdown exerted variable effects on the expression of $A 3 B$ to $A 3 G$ in the tested UCCs.

Transfection of L1_siRNA\#1 diminished overall FL-L1 transcript levels in the analyzed UCC lines by $8 \%(639-\mathrm{V})$ to $42 \%$ (5637) (Figures 2E-H), and was associated with a drop of $A 3 B$ expression by $25 \%$ (5637) to $55 \%$ (VM-CUB1). $A 3 G$ expression was diminished by 14, 47 and $36 \%$ in VM-CUB1, 5637, and SD cells, respectively, and remained unaffected in 639$\mathrm{V}$ cells. However, only minor, negligible effects on $A 3 C, A 3 D$ and $A 3 F$ transcript levels were observed in VM-CUB1, 5637, and SD cells. In $639-\mathrm{V}$ cells, $A 3 C$ expression was unchanged, whereas $A 3 D$ and $A 3 F$ transcript levels were increased by $56 \%$ and $38 \%$, respectively.

Following transfection with L1_siRNA\#2, $A 3 B$ transcript levels remained basically unchanged in 5637, SD, and 639-V cells, but increased in VM-CUB1 cells by approximately twofold. A3C expression was increased in VM-CUB1, SD, and 639-V cells by $70 \%, 45 \%$, and $30 \%$, respectively, but remained unchanged in 5637 cells. An increase in A3D expression was observed in each of the four UCCs and ranged from 12 to $90 \%$, while $A 3 F$ transcript levels were upregulated only in VM-CUB1 and 639-V cells, and remained essentially unaffected in 5637 and SD cells (Figures 2E-H). The knockdown of functional L1 elements was associated with an increase of $A 3 F$ transcript levels in $639-\mathrm{V}$ cells by $44 \%$, but had no meaningful effect on $A 3 F$ expression in the remaining cell lines. L1_siRNA\#2-mediated knockdown of ORF1p-expressing endogenous L1 elements was associated with a strong increase of $A 3 G$ transcript levels in three UCCs ranging from $50 \%$ in the SD line to fourfold in VM-CUB1 cells but had no consequences for $A 3 F$ expression in 5637 cells, and no noteworthy effect on 5637 cells (Figures 2E-H).

In summary, knockdown of functional L1 elements with L1_siRNA\#2 resulted in a general increase of $A 3 C, D, F$, and $G$ transcript levels in three out of four analyzed UCCs, while L1_siRNA\#1-mediated knockdown was associated with a comparable major increase in $A 3 C, A 3 D$, and $A 3 F$ transcript levels only in 639-V cells and a minor increase in VM-CUB1 cells. A decrease of $A 3$ transcript levels was observed only after L1_siRNA\#1-mediated knockdown in 5637 and SD UCCs and was minor, ranging from 10 to $50 \%$ among the $A 3$ genes. Taken together, no consistent correlation between the knockdown of functional endogenous L1 elements and expression of $A 3$ genes could be observed, but knockdown of intact L1s was more often associated with increases rather than decreases of $A 3$ gene expression. In sum, these findings are not consistent with the hypothesis that expression of $A 3$ genes is upregulated in UCCs as a consequence of functional L1s activation. Furthermore, it is currently unclear why the effects of functional L1 knockdown on A3 gene expression differed between L1_siRNA\#1- and L1_siRNA\#2-mediated knockdowns.

\section{Ectopic Expression of Retrotransposition-Competent L1 Elements Has Only Minor Effects on Expression of Selected A3s}

To investigate the consequences of ectopic overexpression of retrotransposition-competent $\mathrm{L} 1$ elements on endogenous $A 3 B$ and $A 3 G$ transcript levels in UCC lines, we next transfected either of the L1 expression plasmids pJM101/L1 $1_{R P}$ and $\mathrm{pAJG101/L} 1_{R P}$ (Supplementary Figure 1) into the cell lines VM-CUB1 and 5637, which are characterized by relatively high and low endogenous L1 transcript levels, respectively (Figure 1). Following transfection, FL-L1 RNA levels increased 2.5- to 3fold in VM-CUB1 cells and by $23 \%$ to $46 \%$ in 5637 cells, as demonstrated by the L1_5'-UTR-specific RT-qPCR assay (Figures 3A,B). To analyze whether ectopic L1 overexpression affects endogenous $A 3$ expression, we quantified $A 3 A, A 3 B$, and $A 3 G$ mRNA levels in the transfected UCCs. We found that expression of $A 3 B$ and $A 3 G$ was slightly increased in VM-CUB1 UCC after transfection with pAJG101/L1 $1_{R P}$, but only $A 3 B$ expression changes reached the level of significance (Figures 3A,B). In 5637 UCC, $A 3 B$ and $A 3 G$ expression was not altered significantly. Of note, $A 3 A$ expression remained undetectable in both cell lines (data not shown).

To study whether ectopic expression of functional L1 elements can induce $A 3 B$ promoter activity, we co-transfected VM-CUB1 and 5637 cells with either of the two A3B promoter luciferase reporter constructs pA3B-120 or pA3B-1200 (Supplementary Figure 2) together with the $\mathrm{L} 1$ expression plasmids $\mathrm{pJM} 101 / \mathrm{L} 1_{R P}$ and $\mathrm{pAJG} 101 / \mathrm{L} 1_{R P}$ or the empty pCEP4 vector as negative control. Activity of the $A 3 B$ promoter encoded by pA3B1200 increased by $\sim 36 \%-42 \%$ and $64 \%-80 \%$, respectively, after co-transfection of the luciferase reporter construct with pJM101/L1 $1_{R P}$ or pAJG101/L1 $1_{R P}$ into VM-CUB1 and 5637 cells relative to the effect of the control vector (Figures 3C,D). This increase in promoter activity is consistent with the increase in endogenous $A 3 B$ mRNA levels by $\sim 27 \%$ after transfection of plasmid pAJG101/L1 $1_{R P}$ in VM-CUB1 cells (Figure 3A). Taken together, induction of $\mathrm{L} 1$ activity has only minor effects on $\mathrm{A} 3 \mathrm{~B}$ expression as well as promoter activity and significant effects are limited to VM-CUB1 UCC with high L1 expression.

\section{A3B Deaminase Activity Is Predominant in UCCs and Not Altered by Ectopic L1 Expression}

We investigated expression and deaminase activity of A3 enzymes suspected to cause mutations during bladder 

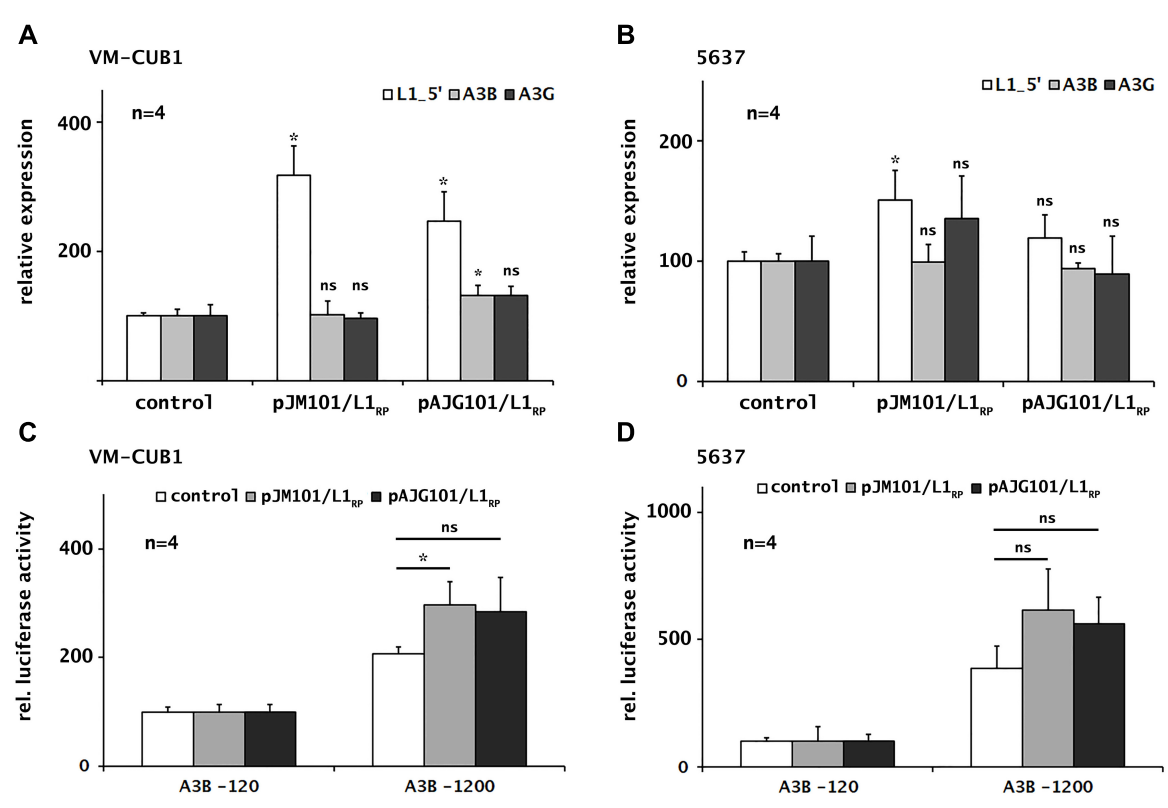

FIGURE 3 | Consequences of ectopic L1 overexpression on endogenous $A 3 B$ and $A 3 G$ transcription and $A 3 B$ promoter activity in selected UCCs. Expression of endogenous and transfected L1 elements, $A 3 B$ and $A 3 G$ was determined in UCCs VM-CUB1 (A) and 5637 (B) after transfection with L1 expression plasmids (pJM101/L1 $1_{R P}$ or pAJG101/L1 $1_{R P}$ ) or control plasmids using RT-qPCR. A3B promoter activity was assessed in VM-CUB1 (C) and 5637 (D) UCCs using luciferase reporter constructs coding for the $A 3 B$ minimal promoter (A3B-120) or $A 3 B$ full promoter (A3B-1200). Promoter constructs were co-transfected with pJM101/L1 RP or pAJG101/L1 $1_{R P}$ expression plasmids or a control plasmid and luciferase activity was assessed subsequently. Luciferase activity values were normalized to luciferase activity data obtained from co-transfection of the A3B-120 minimal promoter construct with the L1 expression construct or the control plasmid, respectively, which were each set as 100. "n" represents the number of independent knock down experiments. Data were presented as means \pm standard deviations (error bars). $P$-values were calculated using Mann-Whitney $U$ Test. Asterisk represents statistically significant difference: ${ }^{*} P<0.05$ and ns, not significant.

carcinogenesis in selected UCCs with different $A 3$ mRNA expression levels. We chose specifically (i) the UCC 5637 exhibiting major transcriptional upregulation of $A 3 B$ and $A 3 G$, (ii) UMUC3 showing robust transcript levels of most $A 3$ genes (with $A 3 B$ expression being the highest), and (iii) VM-CUB1 with very low transcript levels of most $A 3$ family members except for $A 3 B$ (Figure 1). Distinguishing A3B from A3G by standard immunoblotting techniques is challenging due to the high amino-acid sequence homology between both proteins and their comparable molecular masses (Burns et al., 2015; Jaguva Vasudevan et al., 2018). Therefore, to determine whether $\mathrm{A} 3 \mathrm{~B}$ or $\mathrm{A} 3 \mathrm{G}$ is responsible for any potential deamination activity in these cancer cell lines, A3B and A3G were knocked down separately in different cultures or simultaneously in the same culture. Successful downregulation of $A 3 B$ and $A 3 G$ was confirmed by RT-qPCR using A3B- and A3G-specific primer pairs. Transfection of the UCCs 5637, UMUC3, and VM-CUB1 with $A 3 B$-specific siRNA alone reduced $A 3 B$ expression by $>90 \%$ (Figure 4A). Similarly, A3G expression levels dropped after transfection with $A 3 G$-specific siRNA to below $10 \%$ in all three UCCs (Figure 4A). Simultaneous treatment with $A 3 B$ and $A 3 G$-specific siRNAs resulted in diminished $A 3 B$ and $A 3 G$ mRNA levels in all examined UCCs comparable to those observed after single siRNA treatment (Figure 4A).

Immunoblot analyses of cell extracts isolated from the differently transfected 5637 cells with an anti-A3G antibody (ApoC17) (Kao et al., 2003) reported to cross-react with A3B, detected a $\sim 45 \mathrm{kDa}$ protein in 5637 cells, which is consistent with the predicted molecular weights of both A3B and A3G proteins (Figure 4B) and their mRNA expression pattern in 5637 cells (Figure 1). The intensity of the $45 \mathrm{kDa}$ band was slightly diminished after transfection of the cells with $A 3 B$ specific siRNA, but the band disappeared almost entirely after transfection with A3G-specific siRNA or a combination of both siRNAs (Figure 4B). Expression of the $45-\mathrm{kDa}$ protein was not affected by transfection of control siRNA.

Transfection of $A 3 G$-specific siRNA strongly depleted the amounts of the $45-\mathrm{kDa}$ protein in both UMUC3 and VM-CUB1 cells, whereas the A3B-specific siRNA had only a minor effect on the $45-\mathrm{kDa}$ protein levels in UMUC3 cells and did not affect its expression at all in VM-CUB1 cells (Figure 4B). These findings suggest that the majority of the $45-\mathrm{kDa}$ proteins detected with the anti-A3G antibody represents $A 3 G$. A note of caution on the detection of endogenous A3B: Since a more specific antibody capable of selectively detecting endogenous A3B enzyme in UC cell lines is currently not available, we cannot formally exclude that $\mathrm{A} 3 \mathrm{~B}$ protein is not depleted by $A 3 B$-specific siRNA, despite downregulation of $A 3 B$ mRNA. Of note, A3A expression was not considered because there was no evidence for the presence of $A 3 A$ mRNA in the analyzed UCC lines (Figures 1, 2), and consistently, immunoblot analysis with anti-A3A antibodies did not provide any evidence for the presence of A3A proteins (data not shown).

In order to investigate if $\mathrm{A} 3 \mathrm{~B}$ and/or $\mathrm{A} 3 \mathrm{G}$ are enzymatically active in UCC lines, DNA deamination activity assays were 


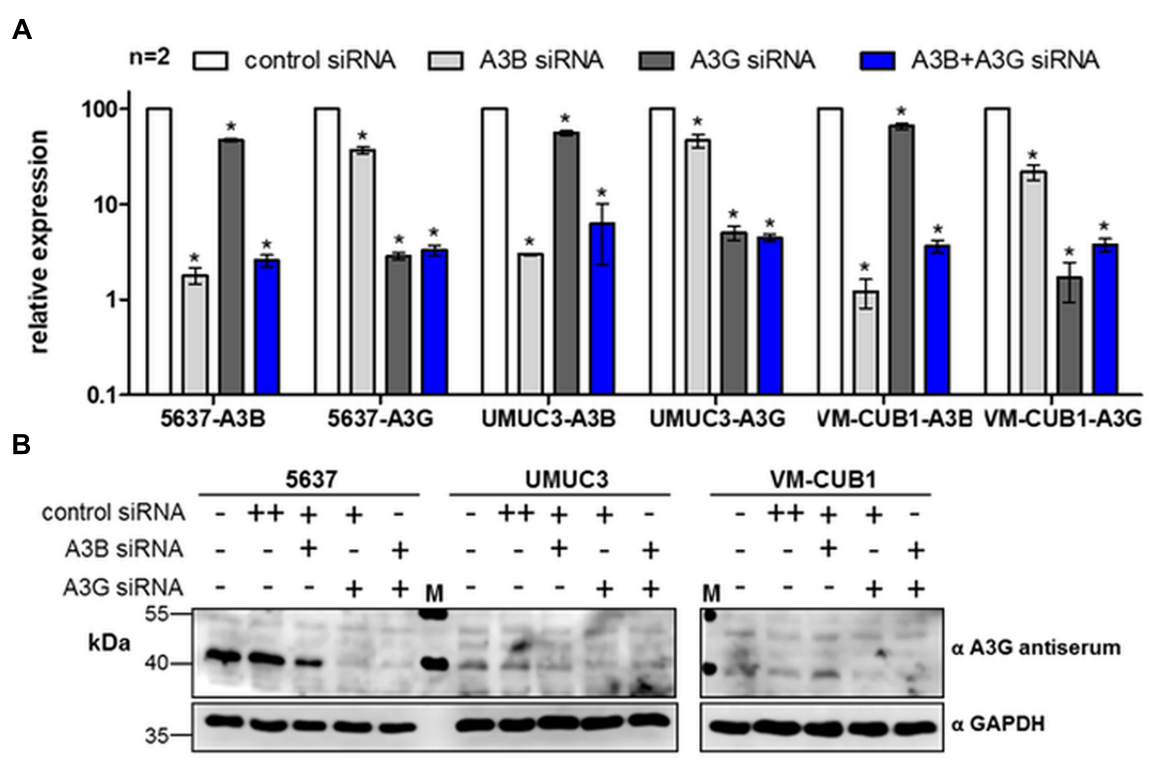

C

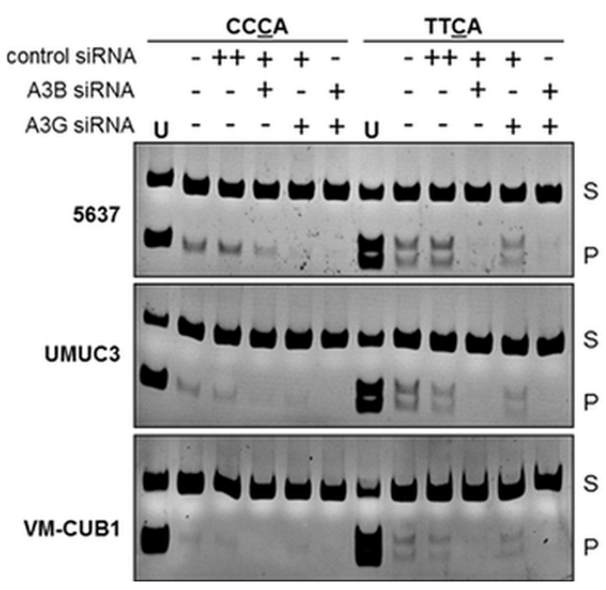

D

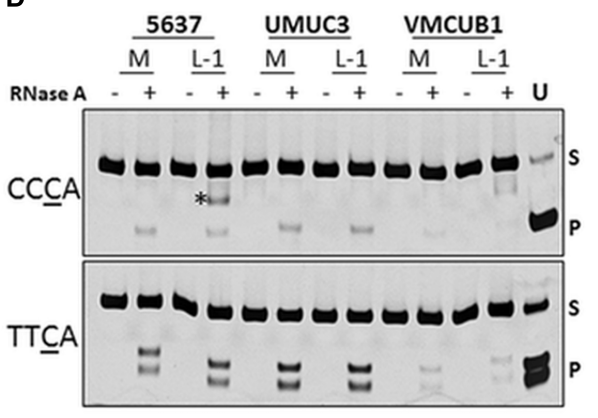

FIGURE 4 | Expression and in vitro deamination activity of endogenous A3B and A3G in cell lysates of UC cell lines. (A) RT-qPCR analysis of A3B and A3G transcripts in 5637, UMUC3, and VM-CUB1 UCCs transfected with control, A3B- or A3G-specific siRNAs as indicated. UCCS were incubated for $72 \mathrm{~h}$ with a final siRNA concentration of $20 \mathrm{nM}$. Values are means \pm standard deviations (error bars) obtained from two independent transfection experiments $(n=2)$. $P$-values were calculated using unpaired $t$-tests and statistical significant changes $(p<0.05)$ are indicated by asterisks $(*)$. (B) Immunoblot analysis of endogenous A3B and A3G expression in 5637, UMUC3, and VM-CUB1 UCCs after transfection with control, A3B- or A3G-specific siRNAs for $72 \mathrm{~h}$ as indicated. GAPDH expression served as loading control. M, molecular weight standard. (C) Deamination activity of siRNA-treated and untreated samples as described in (B), was assessed by in vitro DNA deamination assay. The enzymatic activity of endogenous A3B and A3G proteins was tested on two different oligonucleotide substrates containing either the CCCA or TTCA motif. All reactions were treated with RNAse A to derive physiologically active A3 proteins from higher mass RNA complexes. Deamination product band (P) and substrate band (S) are marked. As a deamination product marker and as a restriction enzyme control, substrates containing the CCUA or TTUA motif were cleaved by their respective restriction enzyme and loaded on the gel (U). (D) Deamination activity of protein extracts isolated from UCCs 5637, UMUC3, and VM-CUB1 that were transfected with the Mock-control (M) or PAJG101/L1 RP plasmid was investigated. RNAse A-untreated and treated samples were included. "*" indicates an unspecific band. To validate substrate-specific A3 deamination activity, the assay was performed using protein extracts from $293 \mathrm{~T}$ cells previously transfected with A3B or A3G expression plasmids, respectively (Supplementary Figure 5).

performed using cells lysates from the different UCCs transfected with $A 3 B$ - and $A 3 G$-siRNAs as controls (Figure 4C). To measure deaminase activity, we applied a qualitative PCR-based in vitro DNA deamination assay to identify $\mathrm{C} \rightarrow \mathrm{U}$ conversion in an 80-nt single-stranded DNA substrate harboring the isozymespecific motif TTCEA or CCㅡA, specifically recognized by A3B or A3G, respectively (Jaguva Vasudevan et al., 2017; Yang et al., 2017). Catalytic deamination of $\mathrm{C} \rightarrow \mathrm{U}$ in the respective motif creates specific restriction sites, which can be detected by restriction analysis of the PCR product. As an additional control, substrate specificity of $\mathrm{A} 3 \mathrm{~B}$ and $\mathrm{A} 3 \mathrm{G}$ was tested using lysates from 293 T cells transiently transfected with A3B or A3G expression plasmids (Supplementary Figure 5). Of note, whereas the substrate TTCA (YTCAA) was reported as a statistically 


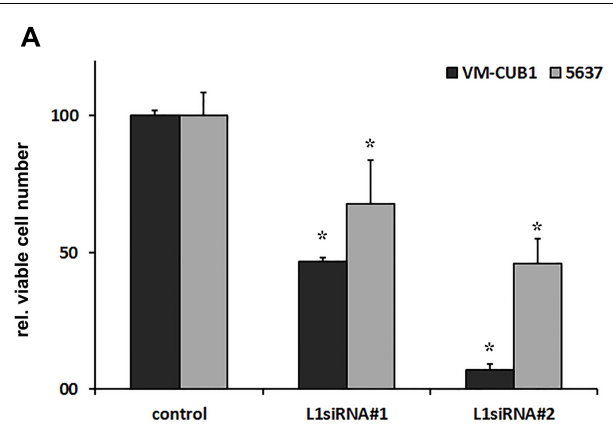

C

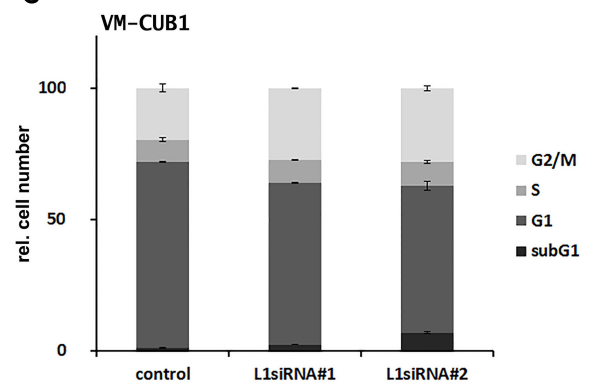

B

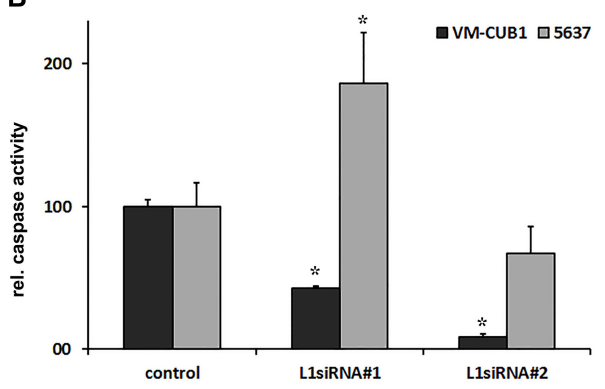

D

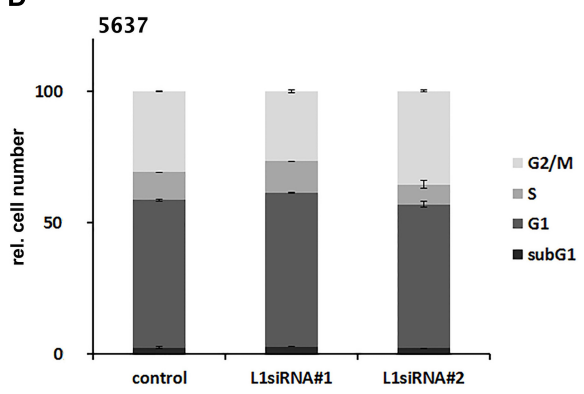

FIGURE 5 | Phenotypical consequences of L1 siRNA treatment in selected UCCs. (A) Cell viability and (B) caspase activity (both depicted as percent of control) were determined in VM-CUB1 and 5637 UCCs after $72 \mathrm{~h}$ treatment with $20 \mathrm{nM}$ control siRNA or L1 siRNAs (each $n=5-8$ ). Cell cycle distribution in (C) VM-CUB1 and (D) 5637 cells (each $n=2$ ). Data were represented as means \pm standard deviations (error bars). $P$-values for $(\mathbf{A}, \mathbf{B})$ were calculated using Mann-Whitney $U$ Test. Asterisk represents statistically significant difference: ${ }^{*} P<0.05$ and ns, not significant.

favorable target for $\mathrm{A} 3 \mathrm{~A}$ over $\mathrm{A} 3 \mathrm{~B}$ in cancer tissues (Chan et al., 2015), TTC was demonstrated as a preferred target for all A3s except for A3G, in vitro, based on high resolution structures, protein-DNA interaction studies, and enzymatic assays (Yu et al., 2004; Harjes et al., 2017; Jaguva Vasudevan et al., 2017; Kouno et al., 2017; Shi et al., 2017; Yang et al., 2017). The assay demonstrated that A3G deaminase activity is present in all three UCCs (Figure 4C, CCCA panel). A3G deaminase activity was robust in 5637 cells, but lower in UMUC3 cells and barely detectable in VM-CUB1 cells. Importantly, as expected from the CCCA substrate specificity of A3G (Yu et al., 2004; Jaguva Vasudevan et al., 2017), siRNA-mediated knockdown of $\mathrm{A} 3 \mathrm{G}$ affected product formation in the CCCA assay more efficiently than in the TTCA assay (Figure 4C). Using the CCCA substrate, A3B downregulation slightly reduced product formation, whereas simultaneous knockdown of A3B and $\mathrm{A} 3 \mathrm{G}$ abolished detectable deaminase activity. Conversely, using the TTCA substrate, A3B knockdown, but not A3G knockdown resulted in complete loss of detectable deaminase activity (Figure 4C, TTCA panel). Taken together, these data confirm that $\mathrm{A} 3 \mathrm{G}$ favors the CCCA sequence motif and $\mathrm{A} 3 \mathrm{~B}$ prefers the TTCA motif, but also indicate that $\mathrm{A} 3 \mathrm{~B}$ might mutate CCCA sequences on ssDNA substrates with a low frequency. More importantly, combining the deamination assay data (Figure 4C) with the A3 expression data presented in Figures 1 and $4 \mathrm{~A}$ leads to the conclusion that in vitro $\mathrm{A} 3 \mathrm{~B}$ is the predominantly active member of the A3 family in the tested UCCs, whereas A3G-specific deaminase activity is comparably low.
Next, we investigated the effect of the expression of functional L1 elements on the deamination activity of A3 proteins by ectopically overexpressing transfected functional L1 elements encoded by pAJG101/L1 $1_{R P}$ in UCCs. Lysates from transfected and untransfected UCCs were then either treated with RNase A to eliminate potential inhibitory RNA molecules, or left untreated, before they were assayed for A3B- or A3G-specific deaminase activity (Soros et al., 2007; McDougall and Smith, 2011). Ectopic L1 expression did not affect A3B- or A3G-encoded deaminase activity in any of the transfected UCC lines (Figure 4D).

\section{L1 Downregulation Reduces Cell Viability Irrespective of Apoptosis and Induces Senescence in UCC}

While our results do not indicate that L1 expression affects A3B (or other A3) expression consistently, L1 silencing by siRNA impaired cell proliferation. In VM-CUB1 cells expressing L1 more strongly, the number of viable cells decreased to $47 \%$ and $7 \%$ after L1 knockdown using L1_siRNA\#1 and L1_siRNA\#2, respectively, compared to control siRNAtransfected cells (Figure 5A). The number of viable 5637 UCCs was less severely depleted to $68 \%$ and $46 \%$ after treatment with L1_siRNA\#1 and L1_siRNA\#2, respectively (Figure 5A). Caspase $3 / 7$ activity, measured as an indicator of apoptosis, decreased to $43 \%$ and $8 \%$ in VM-CUB1 cells after L1_siRNA\#1 and L1_siRNA\#2 treatment, respectively (Figure 5B). In 5637 UCCs, caspase activity was increased after treatment with L1_siRNA\#1, but not with L1_siRNA\#2 (Figure 5B). According to flow 
cytometry data, the fraction of VM-CUB1 cells in G2/M phase was increased by roughly $8 \%$ in cells treated with either $\mathrm{L} 1$ siRNA (Figure 5C). In VM-CUB1 cells treated with L1_siRNA\#2, the fraction of subG1 cells also decreased. S-phase fraction was unchanged (Figure 5C) and accordingly, incorporation of EdU was only slightly diminished, especially following L1_siRNA\#1 treatment (Supplementary Figure 6A). Only minor changes in cell cycle distribution and, accordingly, EdU incorporation were seen in 5637 UCCs (Figure 5D and Supplementary Figure 6A). Thus, the decrease in viable cells following L1 knockdown does not reflect apoptosis.

In keeping with its effects on cell viability in shortterm experiments, FL-L1 knockdown strongly diminished the clonogenicity of VM-CUB1 cells (Supplementary Figure 6B). Moreover, some VM-CUB1 cells showed morphological changes typical of senescent cells and stained positive for senescenceassociated (SA)- $\beta$-galactosidase after treatment with either L1 siRNA, but very rarely after treatment with control siRNA (Supplementary Figure 6D). Unexpectedly, in 5637 cells, clonogenicity reproducibly increased after L1 knockdown using L1_siRNA\#2, whereas L1_siRNA\#1 exerted no significant effects on clonogenicity (Supplementary Figure 6C). Accordingly, no indications of senescence were detected in 5637 cells after treatment with L1 siRNAs or control siRNA (data not shown). Thus, L1 knockdown affected VM-CUB1 UCCs with high L1 expression levels more severely than 5637 cells with low L1 expression.

\section{DISCUSSION}

\section{The APOBEC3 Signature in Urothelial Carcinoma}

Mutations induced by misdirected activity of A3 proteins have been implicated in several cancer types (Alexandrov et al., 2013; Burns et al., 2013; Lawrence et al., 2013; Roberts et al., 2013). Following viral replication or in the context of other genomic disturbances, A3 proteins can act as endogenous sources of mutations that can promote genomic instability in cancer evolution (Tubbs and Nussenzweig, 2017). The contribution of $\mathrm{A} 3 \mathrm{~s}$ is especially plausible in cancers elicited by viruses, such as cervical cancer (Henderson et al., 2014), but the high frequency of an APOBEC3related mutational signature in UC (Alexandrov et al., 2013; Lawrence et al., 2013; Roberts et al., 2013) remains unexplained. Indeed, in a recently published molecular characterization of muscle-invasive bladder cancer, it was calculated that APOBEC3-mediated mutagenesis contributes $67 \%$ of all single nucleotide variants (SNVs) (Robertson et al., 2017).

\section{APOBEC Isoenzymes in Urothelial Carcinogenesis}

A specific question is, which member of the A3 protein family is responsible for the observed mutational signature in UC. Bioinformatic analyses suggest that the mutational signature in
UC matches better A3A than A3B specificity (Chan et al., 2015; Lamy et al., 2016). However, the expression of $A 3 B$ was reported to exceed $A 3 A$ expression in UC tissues (Lamy et al., 2016) and $\mathrm{A} 3 \mathrm{~B}$ may be more capable of introducing base substitutions in genomic DNA in human cells (Shinohara et al., 2012). Likewise, our results demonstrated robust upregulation of $A 3 B$ expression in 16/17 UCC lines relative to normal urothelial cell cultures (Figure 1), whereas $A 3 A$ was essentially undetectable in almost all (16/17) analyzed UCCs. Obviously, expression and enzymatic activity of A3 family members may vary during urothelial carcinogenesis and may not be fully reflected in the pattern seen in UCCs. However, A3 mutational activity was shown to be involved in both early and late mutation events that occurred during urothelial carcinogenesis arguing rather for continuous A3 mutational activity (McGranahan et al., 2015; Hurst et al., 2017; Robertson et al., 2017). Accordingly, $A 3 B$ expression levels exceeding $A 3 A$ were also observed in high-grade non-muscle invasive bladder cancers (NMIBCs) (Hedegaard et al., 2016). Furthermore, it seems unlikely that A3A would be selectively repressed in UCCs, whereas A3B remains upregulated. Thus, our results rather argue for the enzymatic activity of $\mathrm{A} 3 \mathrm{~B}$ being responsible for the observed mutations, at least in the context of UCC lines. Conceivably, A3A expression in UC tissues may partly result from macrophages and monocytes highly prevalent in high-grade NMIBCs (Peng et al., 2007; Koning et al., 2009; Thielen et al., 2010; Takeuchi et al., 2016), or may be induced in UC cells in vivo by factors located in the tumor environment. Currently available antibodies directed against $\mathrm{A} 3 \mathrm{~B}$ cannot detect $\mathrm{A} 3 \mathrm{~B}$ at levels present in UCC lines (Burns et al., 2015; Jaguva Vasudevan et al., 2018). However, since we could demonstrate that the amounts of expressed A3G proteins correspond to their $A 3 G$ mRNA levels (Figures 1, 4B) in UCCs 5637, UMUC3 and VM-CUB1, this is very likely to be the case for $\mathrm{A} 3 \mathrm{~B}$ too. Moreover, cytidine deamination assays coupled with knockdown experiments convincingly revealed the expected substratespecific activity levels for both A3B and A3G. Of note, the general DNA motif reported to be recognized by APOBEC proteins to introduce somatic mutations in cancer is "TC" (Roberts et al., 2013) (the A3B-specific motif in our assay here is TTCA). However, A3G recognizes the DNA sequence motif (CCCA) (Jaguva Vasudevan et al., 2013; Yang et al., 2017). In addition, A3G reportedly possesses a cytoplasmic retention signal that retains A3G exclusively in the cytoplasm (Jaguva Vasudevan et al., 2013; Bennett et al., 2008). For these reasons, A3G is not considered to contribute to A3-mediated mutagenesis during carcinogenesis. Interestingly, A3G may influence cancer cell survival via its likely role in DSB repair (Nowarski and Kotler, 2013).

\section{Are There Any Effects of Endogenous L1 Activity on A3 Upregulation in Urothelial Cancer Cells?}

To address the general question of what triggers A3 activation in urothelial cancer cells, we pursued the hypothesis that A3 activation may be elicited by endogenous retroelement activity 
rather than the presence of exogenous viruses. Expression of functional endogenous L1 elements seems a plausible cause for A3 activation, because in urothelial cancer cells, L1 promoter sequences are frequently hypomethylated, and FL-L1 expression is increased even more than in other cancer types (Kreimer et al., 2013; Nusgen et al., 2015). In comparison, neither Alu nor HERV-K sequences are significantly upregulated in UCCs (Kreimer et al., 2013). However, our combined results do not allow drawing the conclusion that L1 activity is a major factor for A3 activation as neither siRNA-mediated downregulation of endogenous FL-L1 elements nor ectopic overexpression of RC-L1 reporter elements led to any consistent and significant alteration in the expression of any A3 protein family member. Only in VM-CUB1 cells the overexpression of the L1 reporter plasmid pAJG101/L1 $1_{R P}$ led to a significant increase of A3B transcript levels (Figure 3 ). In addition, endogenous FL-L1 and A3 expression levels did not correlate with each other across the tested panel of cell lines. Here, future investigations are required to unambiguously elucidate any role of L1 expression and/or retrotransposition activity in the activation of $\mathrm{A} 3$ proteins in tumor cells.

For instance, it might be useful to investigate the effects of the codon-optimized L1 element, ORFeus-Hs (An et al., 2011) that produces 5 - to 10 -fold more $\mathrm{L} 1$ proteins than the $\mathrm{L} 1_{R P}$ element used in our study, on the expression of endogenous APOBEC3 gene products.

Knocking down the expression of endogenous FL-L1 elements with two different siRNAs targeting the intact ORF1 coding region resulted in the efficient depletion of endogenous L1 ORF1p. This observation indicates that the majority of transcripts from active L1Hs elements harboring intact ORF1 sequences were removed from the tested cell lines. However, these siRNAs did not decrease the overall FL-L1 transcript levels as measured by RT-qPCR to the same degree (Figure 2). This could be explained by the fact that the L1 5'UTR-specific primers used for the RT-qPCR assay also detect transcripts from FL-L1 elements with non-functional ORF1 sequences, which are not or less efficiently targeted by the siRNAs.

In future work, it should be worthwhile investigating the impact of siRNAs targeting also non-functional L1 transcripts on A3 expression as well.

Although we did not observe any effect of L1 repression on A3 activity, it is obviously capable to elicit severe effects in UCCs. In particular, efficient knockdown of ORF1p expressing FL-L1 elements by siRNAs diminished proliferation of UCCs with higher L1 expression levels (such as VM-CUB1), but had less effect on UCCs exhibiting lower L1 expression levels (such as 5637 cells). These results are in good agreement with previous reports that L1 knockdown causes a loss of proliferative ability in tumor cells independent from apoptosis (Aschacher et al., 2016), ultimately leading to senescence (Oricchio et al., 2007; Sciamanna et al., 2014; Aschacher et al., 2016). However, this issue has not been investigated in UCCs previously. Since L1 activation may be particularly prevalent in UC (Nusgen et al., 2015; Whongsiri et al., 2018), this result calls for closer investigations of L1 function in UC carcinogenesis, beyond retrotransposition. There is growing evidence suggesting that expression and retrotransposition of LINE-1 in neoplasms affects transcription initiation of oncogenes (Rodic and Burns, 2013). Also in hepatocellular carcinoma, L1 ORF1p was suggested to promote cell proliferation and resistance to chemotherapy (Feng et al., 2013). Indeed, L1 expression is linked to the activation of epithelial-mesenchymal transition (EMT) and was shown to affect the expression of miRNA genes (let-7 miRNA family) specifically regulating tumor suppressor expression (Rangasamy et al., 2015). Consistently, our study found cell growth impairment as a consequence of L1 silencing in UCCs, which requires further studies to identify any specific factor(s) or pathway that is involved in this regulation.

\section{Potential Causes of APOBEC Activation in Urothelial Carcinoma}

Finally, if there is no evidence that A3 activation in UC is elicited by either exogenous virus infection or endogenous L1 retrotransposon activation, what causes it? Several alternative hypotheses deserve investigation. For instance, A3B is induced by several cytokines in normal liver (Lucifora et al., 2014) and through the PKC-NFKB signaling pathway in several cancers (Leonard et al., 2015). These factors may also be relevant in urothelial carcinogenesis and could be fostered by a persistent inflammatory state (Thompson et al., 2015). Interestingly, a recent analysis of A3 expression in UC tissues by Glaser et al. (2018) revealed rather uniform expression of $\mathrm{A} 3 \mathrm{~B}$ in various molecular subtypes of the disease, whereas $\mathrm{A} 3 \mathrm{~A}$ was mostly expressed in the basal, squamous-like subtype. A3-high tumors demonstrated higher expression of relevant immune marker genes. A3 genes are inducible by interferon and thus belong to the group of interferon-stimulated genes (ISGs). Indeed, Glaser et al. (2018) could induce A3B expression in the UC cell lines HT-1376 and UMUC3 by IFN $\gamma$ treatment, but not in two cell lines with initially low A3B expression. Unfortunately, they did not report on A3A expression in UC cell lines.

Most advanced muscle-invasive UCs contain mutations inactivating $\mathrm{p} 53$, which are rare in non-muscle invasive UC (Hurst et al., 2017; Robertson et al., 2017). The p53 tumor suppressor also regulates the transcription of several A3 genes. In particular, loss of p53 or overexpression of gain-of-function mutants leads to upregulation of A3B (Menendez et al., 2017; Periyasamy et al., 2017). Loss of p53 function may therefore contribute to $\mathrm{A} 3 \mathrm{~B}$ activation in muscle-invasive $\mathrm{UC}$, but not likely in non-muscle invasive tumors.

Moreover, recent results suggest that $\mathrm{A} 3 \mathrm{~B}$ may target ssDNA accumulating as a result of replication stress (Kanu et al., 2016) or transcription stress (Periyasamy et al., 2015; Tubbs and Nussenzweig, 2017). ssDNA formed preferentially during lagging strand synthesis in the course of DNA replication and displaced non-transcribed strand ssDNA due to transcription overload, e.g., as a result of hormone stimulation (Periyasamy et al., 2015; Haradhvala et al., 2016; Hoopes et al., 2016). Indeed, replication stress is thought to be common during urothelial carcinogenesis (Schepeler et al., 2013) and exacerbated by p53 loss of function. 
Thus, we conclude that several factors may cooperate to activate A3 in urothelial carcinogenesis. This work largely excludes the pervasive activation of L1 retroelements as one potential factor. Moreover, in line with some, but not other previous reports, detailed analysis of UCCs suggests $\mathrm{A} 3 \mathrm{~B}$ rather than $\mathrm{A} 3 \mathrm{~A}$ as the predominantly active enzyme.

The major limitations of our study concern the detection of A3 proteins and the high L1 copy number in the human genome. With respect to $\mathrm{A} 3$ proteins, we could not obtain antibodies that are sufficiently sensitive and specific to detect endogenous expression of each isoenzyme. A reliable array of such antibodies would be very helpful to characterize the expression pattern of A3s in UC cell lines and tissues more precisely. Also the highly repetitive character of endogenous $\mathrm{L} 1$ retroelements causes major complications for our studies. To fully understand the impact of L1 activity in UC cells and tissues, a complete characterization of the repertoire of transcripts from retrotransposition-competent L1 elements and, ideally, from non-functional L1 elements will be required. Third generation techniques currently under development will hopefully enable this investigation.

\section{AUTHOR CONTRIBUTIONS}

WG, WS, AAJV, and CM conceived and designed the experiments. AV and WG performed most of the experiments. GS performed immunoblot analyses, generated the L1 reporter plasmid pAJG101/L1 $1_{R P}$, and participated in drafting the manuscript. UK and AK performed some experiments. WG,

\section{REFERENCES}

Alexandrov, L. B., Nik-Zainal, S., Wedge, D. C., Aparicio, S. A., Behjati, S., Biankin, A. V., et al. (2013). Signatures of mutational processes in human cancer. Nature 500, 415-421. doi: 10.1038/nature12477

An, W., Dai, L., Niewiadomska, A. M., Yetil, A., O’donnell, K. A., Han, J. S., et al. (2011). Characterization of a synthetic human LINE-1 retrotransposon ORFeus-Hs. Mob. DNA 2:2. doi: 10.1186/1759-8753-2-2

Aschacher, T., Wolf, B., Enzmann, F., Kienzl, P., Messner, B., Sampl, S., et al. (2016). LINE-1 induces hTERT and ensures telomere maintenance in tumour cell lines. Oncogene 35, 94-104. doi: 10.1038/onc.2015.65

Bennett, R. P., Presnyak, V., Wedekind, J. E., and Smith, H. C. (2008). Nuclear exclusion of the HIV-1 host defense factor APOBEC3G requires a novel cytoplasmic retention signal and is not dependent on RNA binding. J. Biol. Chem. 283, 7320-7327. doi: 10.1074/jbc.M708567200

Bishop, K. N., Holmes, R. K., Sheehy, A. M., Davidson, N. O., Cho, S. J., and Malim, M. H. (2004). Cytidine deamination of retroviral DNA by diverse APOBEC proteins. Curr. Biol. 14, 1392-1396. doi: 10.1016/j.cub.2004.06.057

Brouha, B., Schustak, J., Badge, R. M., Lutz-Prigge, S., Farley, A. H., Moran, J. V., et al. (2003). Hot L1s account for the bulk of retrotransposition in the human population. Proc. Natl. Acad. Sci. U.S.A. 100, 5280-5285. doi: 10.1073/pnas. 0831042100

Burns, K. H. (2017). Transposable elements in cancer. Nat. Rev. Cancer 17, 415-424. doi: 10.1038/nrc.2017.35

Burns, M. B., Leonard, B., and Harris, R. S. (2015). APOBEC3B: pathological consequences of an innate immune DNA mutator. Biomed. J. 38, 102-110. doi: $10.4103 / 2319-4170.148904$

Burns, M. B., Temiz, N. A., and Harris, R. S. (2013). Evidence for APOBEC3B mutagenesis in multiple human cancers. Nat. Genet. 45, 977-983. doi: 10.1038/ ng. 2701
WS, AAJV, DH, and CM analyzed the data. WS, GS, and CM contributed reagents and tools. WG, WS, AAJV, GS, and CM wrote the paper.

\section{FUNDING}

This study was financially supported by a grant from the Forschungskommission der Medizinischen Fakultät der HHU Düsseldorf to WG, grant SCHU1014/8-1 from the Deutsche Forschungsgemeinschaft to GS, and is supported by the HeinzAnsmann Foundation for AIDS research to CM.

\section{ACKNOWLEDGMENTS}

We are grateful to Michèle J. Hoffmann for advice on cell cycle analysis and several other experiments and to Christiane Hader and Zhang Zeli for helpful discussions. The following reagents were obtained through the NIH AIDS Research and Reference Reagent Program, Division of AIDS, NIAID, NIH: anti-ApoC17, from Klaus Strebel and Anti-Human APOBEC3H Monoclonal (P1H6) (cat \# 12156) from Michael Emerman and Reuben Harris.

\section{SUPPLEMENTARY MATERIAL}

The Supplementary Material for this article can be found online at: https://www.frontiersin.org/articles/10.3389/fmicb. 2018.02088/full\#supplementary-material

Carreira, P. E., Richardson, S. R., and Faulkner, G. J. (2014). L1 retrotransposons, cancer stem cells and oncogenesis. FEBS J. 281, 63-73. doi: 10.1111/febs.12601

Chan, K., Roberts, S. A., Klimczak, L. J., Sterling, J. F., Saini, N., Malc, E. P., et al. (2015). An APOBEC3A hypermutation signature is distinguishable from the signature of background mutagenesis by APOBEC3B in human cancers. Nat. Genet. 47, 1067-1072. doi: 10.1038/ng.3378

Chapman, E. J., Williams, S. V., Platt, F. M., Hurst, C. D., Chambers, P., Roberts, P., et al. (2009). Integrated genomic and transcriptional analysis of the in vitro evolution of telomerase-immortalized urothelial cells (TERT-NHUC). Genes Chromosomes Cancer 48, 694-710. doi: 10.1002/gcc.20672

Chiu, Y. L., and Greene, W. C. (2008). The APOBEC3 cytidine deaminases: an innate defensive network opposing exogenous retroviruses and endogenous retroelements. Annu. Rev. Immunol. 26, 317-353. doi: 10.1146/annurev. immunol.26.021607.090350

Doehle, B. P., Schafer, A., and Cullen, B. R. (2005). Human APOBEC3B is a potent inhibitor of HIV-1 infectivity and is resistant to HIV-1 Vif. Virology 339, 281-288. doi: 10.1016/j.virol.2005.06.005

Doucet-O’Hare, T. T., Rodic, N., Sharma, R., Darbari, I., Abril, G., Choi, J. A., et al. (2015). LINE-1 expression and retrotransposition in Barrett's esophagus and esophageal carcinoma. Proc. Natl. Acad. Sci. U.S.A. 112, E4894-E4900. doi: $10.1073 /$ pnas. 1502474112

Ewing, A. D., Gacita, A., Wood, L. D., Ma, F., Xing, D., Kim, M. S., et al. (2015). Widespread somatic L1 retrotransposition occurs early during gastrointestinal cancer evolution. Genome Res. 25, 1536-1545. doi: 10.1101/gr.196238.115

Feng, F., Lu, Y. Y., Zhang, F., Gao, X. D., Zhang, C. F., Meredith, A., et al. (2013). Long interspersed nuclear element ORF-1 protein promotes proliferation and resistance to chemotherapy in hepatocellular carcinoma. World J. Gastroenterol. 19, 1068-1078. doi: 10.3748/wjg.v19.i7.1068

Glaser, A. P., Fantini, D., Wang, Y., Yu, Y., Rimar, K. J., Podojil, J. R., et al. (2018). APOBEC-mediated mutagenesis in urothelial carcinoma is associated with 
improved survival, mutations in DNA damage response genes, and immune response. Oncotarget 9, 4537-4548. doi: 10.18632/oncotarget.23344

Goering, W., Ribarska, T., and Schulz, W. A. (2011). Selective changes of retroelement expression in human prostate cancer. Carcinogenesis 32, 14841492. doi: $10.1093 /$ carcin/bgr 181

Goodier, J. L. (2014). Retrotransposition in tumors and brains. Mob. DNA 5:11. doi: $10.1186 / 1759-8753-5-11$

Goodier, J. L., and Kazazian, H. H. Jr. (2008). Retrotransposons revisited: the restraint and rehabilitation of parasites. Cell 135, 23-35. doi: 10.1016/j.cell.2008. 09.022

Haradhvala, N. J., Polak, P., Stojanov, P., Covington, K. R., Shinbrot, E., Hess, J. M., et al. (2016). Mutational strand asymmetries in cancer genomes reveal mechanisms of DNA damage and repair. Cell 164, 538-549. doi: 10.1016/j.cell. 2015.12.050

Harjes, S., Jameson, G. B., Filichev, V. V., Edwards, P. J. B., and Harjes, E. (2017). NMR-based method of small changes reveals how DNA mutator APOBEC3A interacts with its single-stranded DNA substrate. Nucleic Acids Res. 45, 56025613. doi: 10.1093/nar/gkx196

Harris, R. S., and Dudley, J. P. (2015). APOBECs and virus restriction. Virology 479-480, 131-145. doi: 10.1016/j.virol.2015.03.012

Hedegaard, J., Lamy, P., Nordentoft, I., Algaba, F., Hoyer, S., Ulhoi, B. P., et al. (2016). Comprehensive transcriptional analysis of early-stage urothelial carcinoma. Cancer Cell 30, 27-42. doi: 10.1016/j.ccell.2016.05.004

Henderson, S., Chakravarthy, A., Su, X., Boshoff, C., and Fenton, T. R. (2014). APOBEC-mediated cytosine deamination links PIK3CA helical domain mutations to human papillomavirus-driven tumor development. Cell Rep. 7, 1833-1841. doi: 10.1016/j.celrep.2014.05.012

Henderson, S., and Fenton, T. (2015). APOBEC3 genes: retroviral restriction factors to cancer drivers. Trends Mol. Med. 21, 274-284. doi: 10.1016/j.molmed. 2015.02.007

Hoffmann, M. J., Muller, M., Engers, R., and Schulz, W. A. (2006). Epigenetic control of CTCFL/BORIS and OCT4 expression in urogenital malignancies. Biochem. Pharmacol. 72, 1577-1588. doi: 10.1016/j.bcp.2006.06.020

Hoopes, J. I., Cortez, L. M., Mertz, T. M., Malc, E. P., Mieczkowski, P. A., and Roberts, S. A. (2016). APOBEC 3 A and APOBEC3B preferentially deaminate the lagging strand template during DNA replication. Cell Rep. 14, 1273-1282. doi: 10.1016/j.celrep.2016.01.021

Horn, A. V., Klawitter, S., Held, U., Berger, A., Jaguva Vasudevan, A. A., Bock, A., et al. (2013). Human LINE-1 restriction by APOBEC3C is deaminase independent and mediated by an ORF1p interaction that affects LINE reverse transcriptase activity. Nucleic Acids Res. 42, 396-416. doi: 10.1093/nar/gkt898

Hurst, C. D., Alder, O., Platt, F. M., Droop, A., Stead, L. F., Burns, J. E., et al. (2017). Genomic subtypes of non-invasive bladder cancer with distinct metabolic profile and female gender bias in KDM6A mutation frequency. Cancer Cell 32:e707. doi: 10.1016/j.ccell.2017.08.005

Iizuka, T., Wakae, K., Nakamura, M., Kitamura, K., Ono, M., Fujiwara, H., et al. (2017). APOBEC3G is increasingly expressed on the human uterine cervical intraepithelial neoplasia along with disease progression. Am. J. Reprod. Immunol. 78:e12703. doi: 10.1111/aji.12703

Itahana, K., Campisi, J., and Dimri, G. P. (2007). Methods to detect biomarkers of cellular senescence: the senescence-associated beta-galactosidase assay. Methods Mol. Biol. 371, 21-31. doi: 10.1007/978-1-59745-361-5_3

Jaguva Vasudevan, A. A., Goering, W., Häussinger, D., and Münk, C. (2018). Detection of APOBEC3 proteins and catalytic activity in urothelial carcinoma. Methods Mol. Biol. 1655, 97-107. doi: 10.1007/978-1-4939-7234-0_8

Jaguva Vasudevan, A. A., Hofmann, H., Willbold, D., Häussinger, D., Koenig, B. W., and Münk, C. (2017). Enhancing the catalytic deamination activity of APOBEC3C is insufficient to inhibit Vif-deficient HIV-1. J. Mol. Biol. 429, 1171-1191. doi: 10.1016/j.jmb.2017.03.015

Jaguva Vasudevan, A. A., Perkovic, M., Bulliard, Y., Cichutek, K., Trono, D., Häussinger, D., et al. (2013). Prototype foamy virus Bet impairs the dimerization and cytosolic solubility of human APOBEC3G. J. Virol. 87, 9030-9040. doi: 10.1128/JVI.03385-12

Kanu, N., Cerone, M. A., Goh, G., Zalmas, L. P., Bartkova, J., Dietzen, M., et al. (2016). DNA replication stress mediates APOBEC3 family mutagenesis in breast cancer. Genome Biol. 17:185. doi: 10.1186/s13059-016-1042-9

Kao, S., Khan, M. A., Miyagi, E., Plishka, R., Buckler-White, A., and Strebel, K. (2003). The human immunodeficiency virus type 1 Vif protein reduces intracellular expression and inhibits packaging of APOBEC3G (CEM15), a cellular inhibitor of virus infectivity. J. Virol. 77, 11398-11407. doi: 10.1128/ JVI.77.21.11398-11407.2003

Kimberland, M. L., Divoky, V., Prchal, J., Schwahn, U., Berger, W., and Kazazian, H. H. Jr. (1999). Full-length human L1 insertions retain the capacity for high frequency retrotransposition in cultured cells. Hum. Mol. Genet. 8, 1557-1560. doi: $10.1093 / \mathrm{hmg} / 8.8 .1557$

Kobayashi, M. (1996). Improved dicistronic mRNA expressing vectors for efficient selection of transfectants highly expressing foreign genes. Biotechniques 21, 398-402. doi: 10.2144/96213bm12

Koch, A., Hatina, J., Rieder, H., Seifert, H. H., Huckenbeck, W., Jankowiak, F., et al. (2012). Discovery of TP53 splice variants in two novel papillary urothelial cancer cell lines. Cell Oncol. 35, 243-257. doi: 10.1007/s13402-012-0082-8

Koning, F. A., Newman, E. N., Kim, E. Y., Kunstman, K. J., Wolinsky, S. M., and Malim, M. H. (2009). Defining APOBEC3 expression patterns in human tissues and hematopoietic cell subsets. J. Virol. 83, 9474-9485. doi: 10.1128/JVI. 01089-09

Kouno, T., Silvas, T. V., Hilbert, B. J., Shandilya, S. M. D., Bohn, M. F., Kelch, B. A., et al. (2017). Crystal structure of APOBEC3A bound to single-stranded DNA reveals structural basis for cytidine deamination and specificity. Nat. Commun. 8:15024. doi: $10.1038 /$ ncomms 15024

Kreimer, U., Schulz, W. A., Koch, A., Niegisch, G., and Goering, W. (2013). HERV$\mathrm{K}$ and LINE-1 DNA methylation and reexpression in urothelial carcinoma. Front. Oncol. 3:255. doi: 10.3389/fonc.2013.00255

Lamy, P., Nordentoft, I., Birkenkamp-Demtroder, K., Thomsen, M. B., Villesen, P., Vang, S., et al. (2016). Paired exome analysis reveals clonal evolution and potential therapeutic targets in urothelial carcinoma. Cancer Res. 76, 58945906. doi: 10.1158/0008-5472.CAN-16-0436

Lawrence, M. S., Stojanov, P., Polak, P., Kryukov, G. V., Cibulskis, K., Sivachenko, A., et al. (2013). Mutational heterogeneity in cancer and the search for new cancer-associated genes. Nature 499, 214-218. doi: 10.1038/ nature 12213

Lee, E., Iskow, R., Yang, L., Gokcumen, O., Haseley, P., Luquette, L. J., et al. (2012). Landscape of somatic retrotransposition in human cancers. Science 337, 967-971. doi: 10.1126/science.1222077

Leonard, B., Mccann, J. L., Starrett, G. J., Kosyakovsky, L., Luengas, E. M., Molan, A. M., et al. (2015). The PKC/NF-kappaB signaling pathway induces APOBEC3B expression in multiple human cancers. Cancer Res. 75, 4538-4547. doi: 10.1158/0008-5472.CAN-15-2171-T

Lucifora, J., Xia, Y., Reisinger, F., Zhang, K., Stadler, D., Cheng, X., et al. (2014). Specific and nonhepatotoxic degradation of nuclear hepatitis B virus cccDNA. Science 343, 1221-1228. doi: 10.1126/science.1243462

McDougall, W. M., and Smith, H. C. (2011). Direct evidence that RNA inhibits APOBEC3G ssDNA cytidine deaminase activity. Biochem. Biophys. Res. Commun. 412, 612-617. doi: 10.1016/j.bbrc.2011.08.009

McGranahan, N., Favero, F., De Bruin, E. C., Birkbak, N. J., Szallasi, Z., and Swanton, C. (2015). Clonal status of actionable driver events and the timing of mutational processes in cancer evolution. Sci. Transl. Med. 7:283ra254. doi: 10.1126/scitranslmed.aaa1408

Menendez, D., Nguyen, T. A., Snipe, J., and Resnick, M. A. (2017). The cytidine deaminase APOBEC3 family is subject to transcriptional regulation by $\mathrm{p} 53$. Mol. Cancer Res. 15, 735-743. doi: 10.1158/1541-7786.MCR-17-0019

Mitra, M., Hercik, K., Byeon, I. J., Ahn, J., Hill, S., Hinchee-Rodriguez, K., et al. (2014). Structural determinants of human APOBEC3A enzymatic and nucleic acid binding properties. Nucleic Acids Res. 42, 1095-1110. doi: 10.1093/nar/ gkt945

Muckenfuss, H., Hamdorf, M., Held, U., Perkovic, M., Lower, J., Cichutek, K., et al. (2006). APOBEC3 proteins inhibit human LINE-1 retrotransposition. J. Biol. Chem. 281, 22161-22172. doi: 10.1074/jbc.M601716200

Münk, C., Willemsen, A., and Bravo, I. G. (2012). An ancient history of gene duplications, fusions and losses in the evolution of APOBEC3 mutators in mammals. BMC Evol. Biol. 12:71. doi: 10.1186/1471-2148-12-71

Niwa, H., Yamamura, K., and Miyazaki, J. (1991). Efficient selection for highexpression transfectants with a novel eukaryotic vector. Gene 108, 193-199. doi: 10.1016/0378-1119(91)90434-D

Nowarski, R., Britan-Rosich, E., Shiloach, T., and Kotler, M. (2008). Hypermutation by intersegmental transfer of APOBEC3G cytidine deaminase. Nat. Struct. Mol. Biol. 15, 1059-1066. doi: 10.1038/nsmb.1495 
Nowarski, R., and Kotler, M. (2013). APOBEC3 cytidine deaminases in doublestrand DNA break repair and cancer promotion. Cancer Res. 73, 3494-3498. doi: 10.1158/0008-5472.CAN-13-0728

Nusgen, N., Goering, W., Dauksa, A., Biswas, A., Jamil, M. A., Dimitriou, I., et al. (2015). Inter-locus as well as intra-locus heterogeneity in LINE-1 promoter methylation in common human cancers suggests selective demethylation pressure at specific CpGs. Clin. Epigenetics 7:17. doi: 10.1186/s13148-0150051-y

Orecchini, E., Frassinelli, L., Galardi, S., Ciafre, S. A., and Michienzi, A. (2018). Post-transcriptional regulation of LINE-1 retrotransposition by AID/APOBEC and ADAR deaminases. Chromosome Res. 26, 45-59. doi: 10.1007/s10577-0189572-5

Oricchio, E., Sciamanna, I., Beraldi, R., Tolstonog, G. V., Schumann, G. G., and Spadafora, C. (2007). Distinct roles for LINE-1 and HERV-K retroelements in cell proliferation, differentiation and tumor progression. Oncogene 26, 42264233. doi: $10.1038 /$ sj.onc. 1210214

Peng, G., Greenwell-Wild, T., Nares, S., Jin, W., Lei, K. J., Rangel, Z. G., et al. (2007). Myeloid differentiation and susceptibility to HIV-1 are linked to APOBEC3 expression. Blood 110, 393-400. doi: 10.1182/blood-2006-10-051763

Periyasamy, M., Patel, H., Lai, C. F., Nguyen, V. T. M., Nevedomskaya, E., Harrod, A., et al. (2015). APOBEC3B-mediated cytidine deamination is required for estrogen receptor action in breast cancer. Cell Rep. 13, 108-121. doi: 10.1016/j.celrep.2015.08.066

Periyasamy, M., Singh, A. K., Gemma, C., Kranjec, C., Farzan, R., Leach, D. A., et al. (2017). p53 controls expression of the DNA deaminase APOBEC3B to limit its potential mutagenic activity in cancer cells. Nucleic Acids Res. 45, 11056-11069. doi: 10.1093/nar/gkx721

Pfaffl, M. W. (2001). A new mathematical model for relative quantification in real-time RT-PCR. Nucleic Acids Res. 29:e45. doi: 10.1093/nar/29.9.e45

Raiz, J., Damert, A., Chira, S., Held, U., Klawitter, S., Hamdorf, M., et al. (2012). The non-autonomous retrotransposon SVA is trans-mobilized by the human LINE-1 protein machinery. Nucleic Acids Res. 40, 1666-1683. doi: 10.1093/nar/ gkr863

Rangasamy, D., Lenka, N., Ohms, S., Dahlstrom, J. E., Blackburn, A. C., and Board, P. G. (2015). Activation of LINE-1 retrotransposon increases the risk of epithelial-mesenchymal transition and metastasis in epithelial cancer. Curr. Mol. Med. 15, 588-597. doi: 10.2174/1566524015666150831130827

Refsland, E. W., and Harris, R. S. (2013). The APOBEC3 family of retroelement restriction factors. Curr. Top. Microbiol. Immunol. 371, 1-27. doi: 10.1007/9783-642-37765-5_1

Roberts, S. A., Lawrence, M. S., Klimczak, L. J., Grimm, S. A., Fargo, D., Stojanov, P., et al. (2013). An APOBEC cytidine deaminase mutagenesis pattern is widespread in human cancers. Nat. Genet. 45, 970-976. doi: 10.1038/ng.2702

Robertson, A. G., Kim, J., Al-Ahmadie, H., Bellmunt, J., Guo, G., Cherniack, A. D., et al. (2017). Comprehensive molecular characterization of muscle-invasive bladder cancer. Cell 171:e525. doi: 10.1016/j.cell.2017.09.007

Rodic, N., and Burns, K. H. (2013). Long interspersed element-1 (LINE-1): passenger or driver in human neoplasms? PLoS Genet. 9:e1003402. doi: 10.1371/ journal.pgen.1003402

Rodic, N., Sharma, R., Sharma, R., Zampella, J., Dai, L., Taylor, M. S., et al. (2014). Long interspersed element-1 protein expression is a hallmark of many human cancers. Am. J. Pathol. 184, 1280-1286. doi: 10.1016/j.ajpath.2014.01.007

Salter, J. D., Bennett, R. P., and Smith, H. C. (2016). The APOBEC protein family: united by structure, divergent in function. Trends Biochem. Sci. 41, 578-594. doi: 10.1016/j.tibs.2016.05.001

Sassaman, D. M., Dombroski, B. A., Moran, J. V., Kimberland, M. L., Naas, T. P., Deberardinis, R. J., et al. (1997). Many human L1 elements are capable of retrotransposition. Nat. Genet. 16, 37-43. doi: 10.1038/ng0597-37

Schepeler, T., Lamy, P., Hvidberg, V., Laurberg, J. R., Fristrup, N., Reinert, T., et al. (2013). A high resolution genomic portrait of bladder cancer: correlation between genomic aberrations and the DNA damage response. Oncogene 32, 3577-3586. doi: 10.1038/onc.2012.381

Schumann, G. G. (2007). APOBEC3 proteins: major players in intracellular defence against LINE-1-mediated retrotransposition. Biochem. Soc. Trans. 35, 637-642. doi: 10.1042/BST0350637

Schumann, G. G., Gogvadze, E. V., Osanai-Futahashi, M., Kuroki, A., Münk, C., Fujiwara, H., et al. (2010). Unique functions of repetitive transcriptomes. Int. Rev. Cell Mol. Biol. 285, 115-188. doi: 10.1016/B978-0-12-381047-2.00003-7
Schwertz, H., Rowley, J. W., Schumann, G. G., Thorack, U., Campbell, R. A., Manne, B. K., et al. (2018). Endogenous LINE-1 (Long interspersed nuclear element-1) reverse transcriptase activity in platelets controls translational events through RNA-DNA hybrids. Arterioscler. Thromb. Vasc. Biol. 38, 801815. doi: 10.1161/ATVBAHA.117.310552

Sciamanna, I., Gualtieri, A., Piazza, P. F., and Spadafora, C. (2014). Regulatory roles of LINE-1-encoded reverse transcriptase in cancer onset and progression. Oncotarget 5, 8039-8051. doi: 10.18632/oncotarget.2504

Seifert, H. H., Meyer, A., Cronauer, M. V., Hatina, J., Muller, M., Rieder, H., et al. (2007). A new and reliable culture system for superficial low-grade urothelial carcinoma of the bladder. World J. Urol. 25, 297-302. doi: 10.1007/s00345-0070166-7

Sheen, F. M., Sherry, S. T., Risch, G. M., Robichaux, M., Nasidze, I., Stoneking, M., et al. (2000). Reading between the LINEs: human genomic variation induced by LINE-1 retrotransposition. Genome Res. 10, 1496-1508. doi: 10.1101/gr.149400

Shi, K., Carpenter, M. A., Banerjee, S., Shaban, N. M., Kurahashi, K., Salamango, D. J., et al. (2017). Structural basis for targeted DNA cytosine deamination and mutagenesis by APOBEC3A and APOBEC3B. Nat. Struct. Mol. Biol. 24, 131-139. doi: $10.1038 / \mathrm{nsmb} .3344$

Shinohara, M., Io, K., Shindo, K., Matsui, M., Sakamoto, T., Tada, K., et al. (2012). APOBEC3B can impair genomic stability by inducing base substitutions in genomic DNA in human cells. Sci. Rep. 2:806. doi: 10.1038/srep00806

Skowronski, J., Fanning, T. G., and Singer, M. F. (1988). Unit-length line-1 transcripts in human teratocarcinoma cells. Mol. Cell. Biol. 8, 1385-1397. doi: 10.1128/MCB.8.4.1385

Soros, V. B., Yonemoto, W., and Greene, W. C. (2007). Newly synthesized APOBEC3G is incorporated into HIV virions, inhibited by HIV RNA, and subsequently activated by RNase H. PLoS Pathog. 3:e15. doi: 10.1371/journal. ppat.0030015

Starrett, G. J., Luengas, E. M., Mccann, J. L., Ebrahimi, D., Temiz, N. A., Love, R. P., et al. (2016). The DNA cytosine deaminase APOBEC3H haplotype I likely contributes to breast and lung cancer mutagenesis. Nat. Commun. 7:12918. doi: $10.1038 /$ ncomms 12918

Swiatkowski, S., Seifert, H. H., Steinhoff, C., Prior, A., Thievessen, I., Schliess, F., et al. (2003). Activities of MAP-kinase pathways in normal uroepithelial cells and urothelial carcinoma cell lines. Exp. Cell Res. 282, 48-57. doi: 10.1006/excr. 2002.5647

Takeuchi, H., Tanaka, M., Tanaka, A., Tsunemi, A., and Yamamoto, H. (2016). Predominance of M2-polarized macrophages in bladder cancer affects angiogenesis, tumor grade and invasiveness. Oncol. Lett. 11, 3403-3408. doi: 10.3892/ol.2016.4392

Tang, Z., Steranka, J. P., Ma, S., Grivainis, M., Rodic, N., Huang, C. R., et al. (2017). Human transposon insertion profiling: analysis, visualization and identification of somatic LINE-1 insertions in ovarian cancer. Proc. Natl. Acad. Sci. U.S.A. 114, E733-E740. doi: 10.1073/pnas.1619797114

Thielen, B. K., Mcnevin, J. P., Mcelrath, M. J., Hunt, B. V., Klein, K. C., and Lingappa, J. R. (2010). Innate immune signaling induces high levels of TC-specific deaminase activity in primary monocyte-derived cells through expression of APOBEC3A isoforms. J. Biol. Chem. 285, 27753-27766. doi: 10. 1074/jbc.M110.102822

Thompson, D. B., Siref, L. E., Feloney, M. P., Hauke, R. J., and Agrawal, D. K. (2015). Immunological basis in the pathogenesis and treatment of bladder cancer. Expert Rev. Clin. Immunol. 11, 265-279. doi: 10.1586/1744666X.2015. 983082

Tolstov, Y., Hadaschik, B., Pahernik, S., Hohenfellner, M., and Duensing, S. (2014). Human papillomaviruses in urological malignancies: a critical assessment. Urol. Oncol. 32, e19-e27. doi: 10.1016/j.urolonc.2013.06.012

Tubbs, A., and Nussenzweig, A. (2017). Endogenous DNA damage as a source of genomic instability in cancer. Cell 168, 644-656. doi: 10.1016/j.cell.2017. 01.002

Vartanian, J. P., Guetard, D., Henry, M., and Wain-Hobson, S. (2008). Evidence for editing of human papillomavirus DNA by APOBEC3 in benign and precancerous lesions. Science 320, 230-233. doi: 10.1126/science.1153201

Vasudevan, A. A., Smits, S. H., Hoppner, A., Häussinger, D., Koenig, B. W., and Münk, C. (2013). Structural features of antiviral DNA cytidine deaminases. Biol. Chem. 394, 1357-1370. doi: 10.1515/hsz-2013-0165

Whongsiri, P., Pimratana, C., Wijitsettakul, U., Jindatip, D., Sanpavat, A., Schulz, W. A., et al. (2018). LINE-1 ORF1 protein is up-regulated by reactive oxygen 
species and associated with bladder urothelial carcinoma progression. Cancer Genomics Proteomics 15, 143-151.

Wissing, S., Montano, M., Garcia-Perez, J. L., Moran, J. V., and Greene, W. C. (2011). Endogenous APOBEC3B restricts LINE-1 retrotransposition in transformed cells and human embryonic stem cells. J. Biol. Chem. 286, 36427-36437. doi: 10.1074/jbc.M111.251058

Yang, B., Li, X., Lei, L., and Chen, J. (2017). APOBEC: from mutator to editor. J. Genet. Genomics 44, 423-437. doi: 10.1016/j.jgg.2017.04.009

Yu, Q., Konig, R., Pillai, S., Chiles, K., Kearney, M., Palmer, S., et al. (2004). Singlestrand specificity of APOBEC3G accounts for minus-strand deamination of the HIV genome. Nat. Struct. Mol. Biol. 11, 435-442. doi: 10.1038/nsmb758
Conflict of Interest Statement: The authors declare that the research was conducted in the absence of any commercial or financial relationships that could be construed as a potential conflict of interest.

Copyright (c) 2018 Jaguva Vasudevan, Kreimer, Schulz, Krikoni, Schumann, Häussinger, Münk and Goering. This is an open-access article distributed under the terms of the Creative Commons Attribution License (CC BY). The use, distribution or reproduction in other forums is permitted, provided the original author(s) and the copyright owner(s) are credited and that the original publication in this journal is cited, in accordance with accepted academic practice. No use, distribution or reproduction is permitted which does not comply with these terms. 